\title{
The rise of working pensioners: the Swedish case $^{\star *}$
}

DOI 10.1515/ntaxj-2016-0003

Received Mar 02, 2016; accepted Apr 23, 2016

\begin{abstract}
According to the Eurostat the old-age dependency (people aged 65 or above relative to those aged 1564) in the EU will rise from $28 \%$ in 2010 to $58 \%$ in 2060. During the same period total hours works are projected to fall contributing to a low projected economic growth over the next half-century. In this paper we argue that this gloomy picture might be challenged by an increase in the employment rates of older workers. Using Sweden as an illustration we show that the ratio of individuals with income from both pension and market work has increased strongly during the last decade. During the same period economic reforms have been introduced creating economic incentives in order to delay the exit from the labor market. In this paper we demonstrate the importance of these economic reforms in explaining increased working hours. The paper also evaluates the fiscal impact of the increase in the employment rates.
\end{abstract}

Keywords: Old age pension; labor supply; tax reforms; microsimulation

\section{Introduction}

This paper describes and analyzes the impact of taxes on the choices people make about working and collection of pension benefits. One rationale for the paper is the recent sharp increase in the number of employed older workers in Sweden. The paper emphasizes the increase of older workers who have both labor and pension income. A main aim of this paper is to explain how much financial incentives have had to do with this change. The evaluation pro-

\footnotetext{
Lennart Flood: Professor emeritus previously at School of Business. Economics and Law, University of Gothenburg, Sweden; Email: fhallene@gmail.com

Nizamul Islam: LISER, Esch-sur-Alzette, Luxembourg; E-mail: nizamul.islam@liser.lu

$\star \star$ The paper was written with the financial support of the Confederation of Swedish Enterprise. Johan Fall and Peter Ericson contributed valuable opinions
}

ceeds from both natural experiments and structural models. One evaluation is based on the effect of targeted tax reductions for older workers implemented in 2007, but an evaluation is also made of an expanded reform in which eligibility for the increased in-work tax credit Jobbskatteavdrag, "JSA") begins at age 61. The evaluation focuses on the effects on employment and public finances, which includes both short-term and long-term assessments. The paper concludes with a summary and a few reflections on future tax policy.

\subsection{Background}

A great deal of attention has been devoted in recent years to the challenges of an aging population. The Swedish national pension system and the tax system have both been designed to encourage deferred pension collection and extended working life. The outcome for pension collection is somewhat fragmented, as the average age for pension collection has remained relatively constant in recent years, while the spread has widened. In parallel, however, the exit age, the age at which the individual stops working, has risen. As a result, the percentage of older workers with both pension and labor income has increased. This paper argues that too much focus has been directed at pension collection when the crucial issue is exit age.

The paper begins with a brief European overview, followed by a more detailed description of the situation in Sweden. The aim of this section is to provide a description of employment and labor income among older workers and shed light on the importance of financial incentives. The statistical input is based on information from the LINDA ${ }^{1}$ database, Statistics Sweden (SCB), the Swedish Pensions Agency and other sources. The microsimulation models SWEtaxben ${ }^{2}$ and SESIM ${ }^{3}$ are used to more closely analyze the impact of financial incentives.

1 Longitudinal individual database compiled by SCB; see Edin and Fredriksson (2000).

2 A static microsimulation model with behavioral effects; see Ericson et al. (2009).

3 A dynamic microsimulation model; see Flood (2008). 


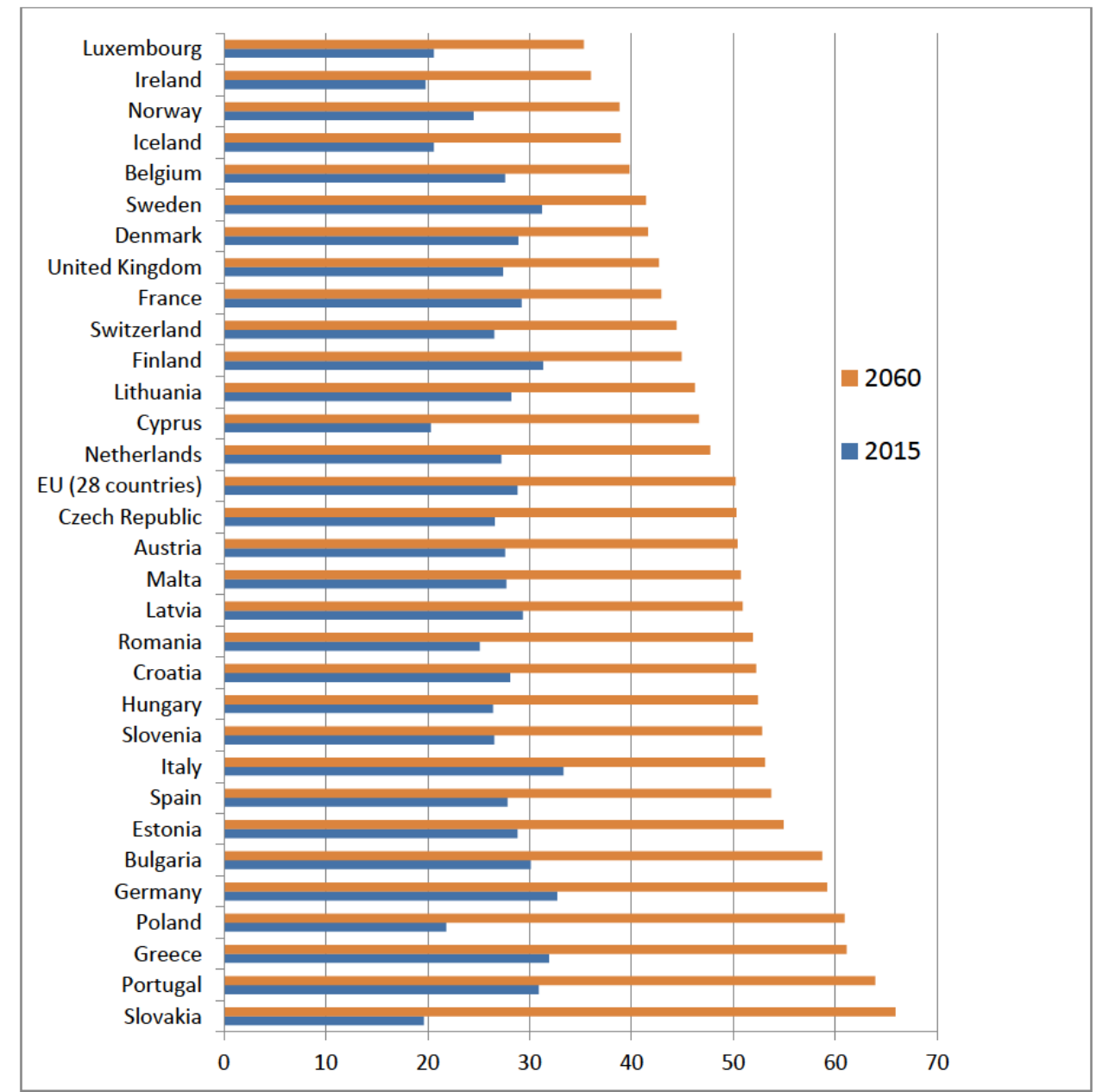

Source: Eurostat - Population Projections EUROPOP2013.

http://ec.europa.eu/eurostat/tgm/table.do?tab=table\&init=1\&plugin=1\&language=en \&pcode=tsdde511

Figure 1: Old-age dependency ratio expressed as a percentage (number of individuals age 65 or older relative to number of individuals of working age), 2015 and 2060. Sorted according to the ratio in 2060.

Finally, an evaluation of the reforms aimed at increasing the labor supply for older workers is presented. Notable among these are the increased JSA for workers older than 65 , as well as reduced payroll taxes (social security contributions). The intent is to provide an extensive description of these effects not only on the labor supply, but also on public finances-both short-term and long-term. The paper concludes with a summary and discussion of how economic policy can be designed with the intention of increasing labor income for the older population.

\subsection{European Overview}

The old-age dependency ratio, which is the number of individuals age 65 or older in relation to those age 15-64, is projected to rise from almost 30 percent to 50 percent on average in the EU by 2060; see Figure 1 . The projection shows wide variation among EU countries. The ratio is expected to be near or below 40 percent in Luxembourg, Ireland, Norway, Iceland, Belgium, Sweden, and Denmark. The corresponding level in countries like Slovakia, Portugal, Greece, Germany, and Bulgaria is 60 percent or higher. Although the ratio in the base year, 2015, is relatively high in Sweden at more than 30 percent, it will be among the lowest in Europe over the long term. Note that Sweden is the country with the lowest increase from 2015 to 2060, just above 10 percentage points. The explanation is a relatively high fertility rate and large net immigration.

Figure 2 shows the change in the employment rate among older workers between 2006 and 2014. Sweden has demonstrated the largest employment growth in this category in Europe. The increase is highest among the richer countries; as shown in the figure, Sweden is followed by 


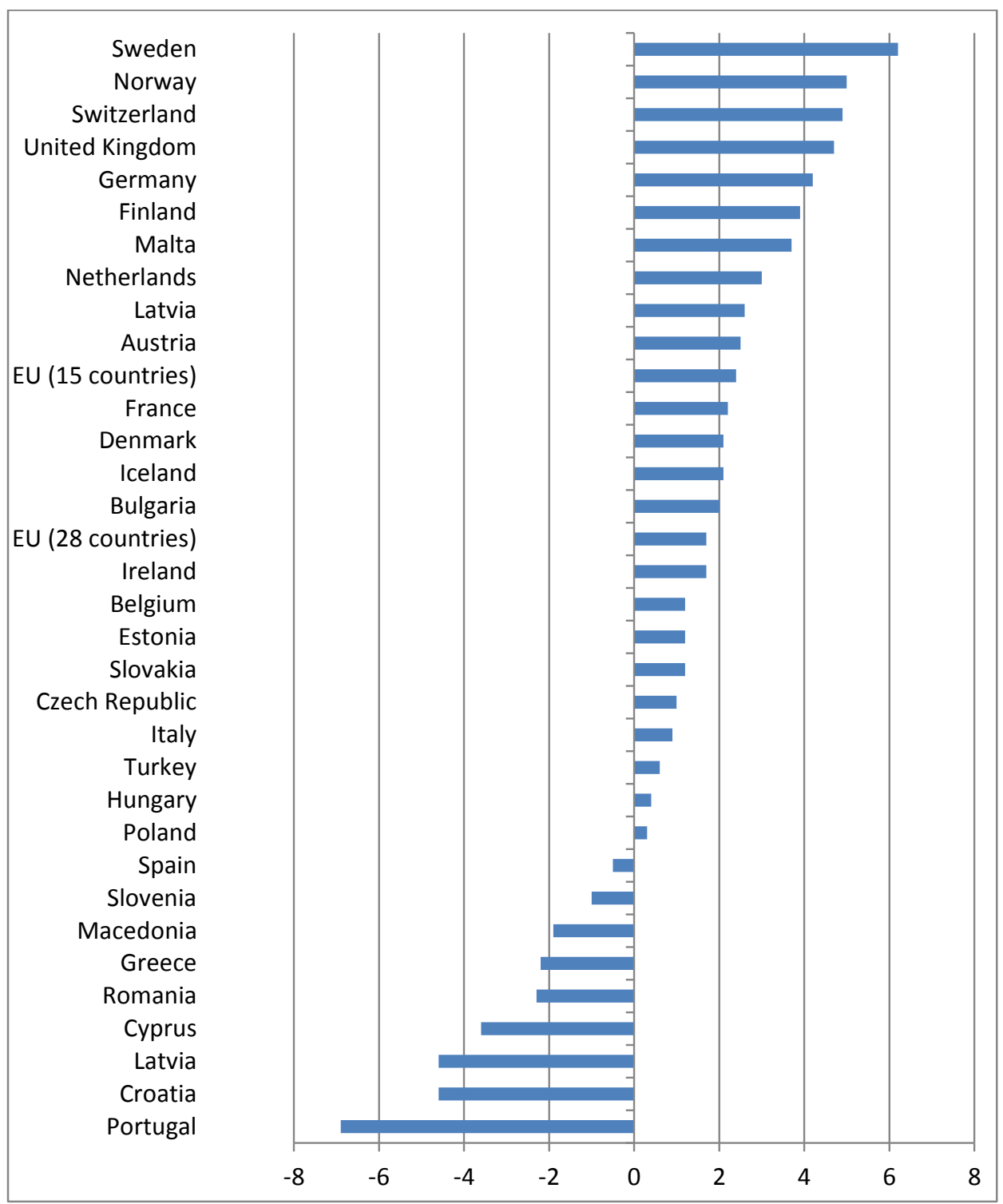

Sources: Skattebetalarna (Swedish Taxpayers Association (2015)) and Eurostat

Figure 2: Change in employment rates for people age 65-74, 2006-2014, percent.

Norway, Switzerland, the UK, and Germany, in that order. Countries such as Portugal, Croatia, and Latvia are found at the other end of the scale.

Figure 3 presents the number of persons who continue working while collecting old-age pension. In 2012, the average in the EU 28 for pension beneficiaries age 50-69 who are still in work was around 16 percent. The highest percentages apply to Norway (38.7\%), Iceland (37.2\%), and Sweden (34.9\%). The lowest percentages of working pension beneficiaries are found in countries such as Greece (1.9\%), Spain (2.1\%), and Belgium (7.0\%).

This brief international overview shows that employment rates for older workers differ sharply from country to country with regard to factors including level, rate of change, and composition. Analyzing explanatory factors behind these differences is beyond the purview of this paper, but the description provides an interesting background and good reason to more closely examine the role of financial incentives in the frequency of gainful employment among older workers. For practical reasons, access to data not least among them, the analysis is limited to Swedish conditions. A somewhat more detailed background description for Sweden is provided in the following. 


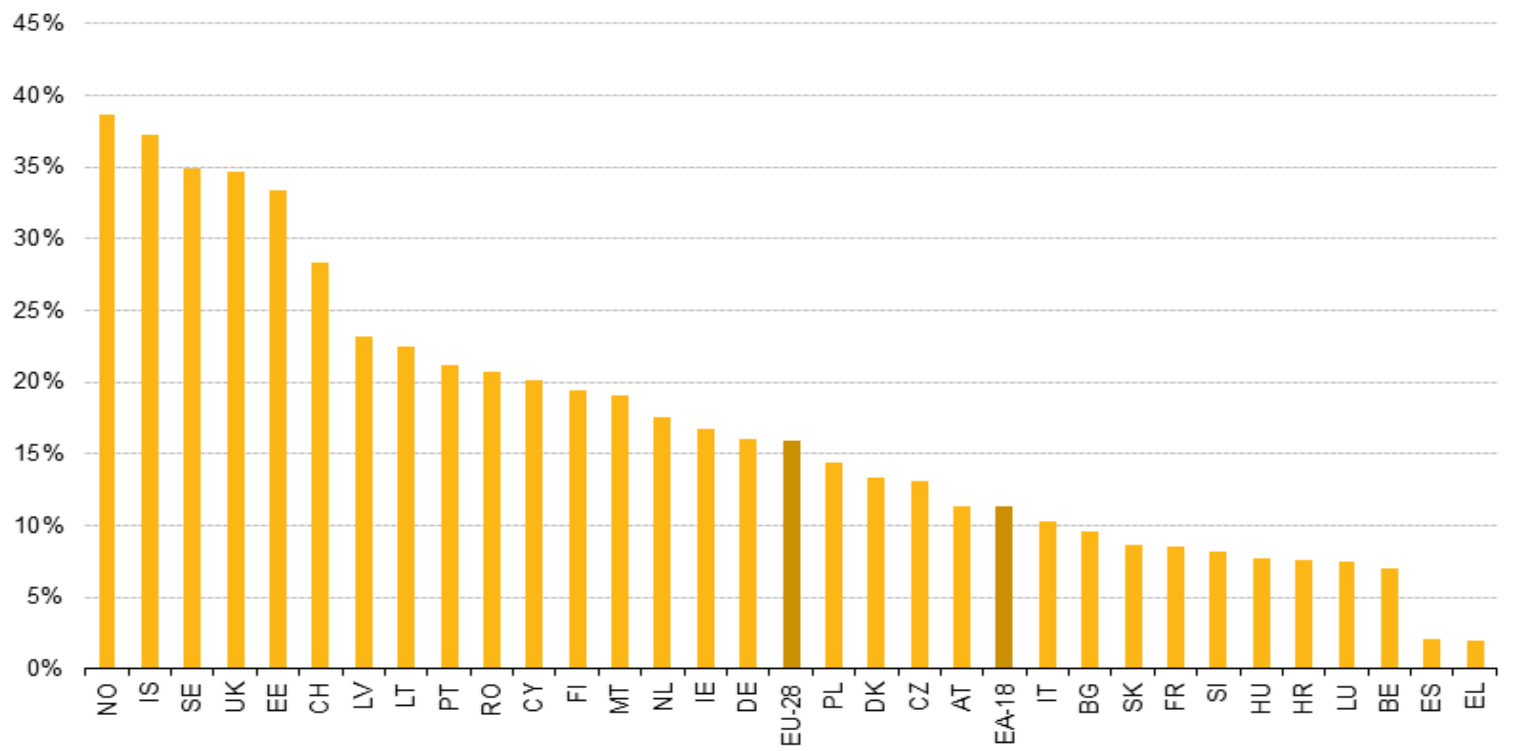

Source: Eurostat, LFS AHM 2012

http://ec.europa.eu/eurostat/statistics-explained/index.php/Labour_force_survey_statistics_-_transition_from_work_to_retirement

Figure 3: Percentage of working pension beneficiaries age 50-69 in 2012.

\subsection{Labor Supply for Older Workers in Sweden}

The age of retirement may be defined as the age at which an individual exits the labor market or the age at which an individual is granted or begins to collect a pension benefit. The Pensions Agency calls the first the "exit age" and the latter the "pension age."

Each year, the Pensions Agency publishes four measures to shed light on exit and retirement. Three different measures for the "average pension age" and one measure of the "expected exit age." The first definition of the average pension age is simply the average age at which people begin collecting their pensions, which was 64.5 years in 2013 according to the Pensions Agency. The two alternative definitions also include people who were granted sickness compensation at age 30-49 or after age 50, respectively. This results in an average pension age of 62.3 and 63.9 years, respectively. The reason for including sickness compensation is that for many people, this compensation may be regarded as an early pension and for older workers receiving sickness compensation, the benefit is converted at age 65 to the national pension, in many cases the guarantee pension. When the upper limit of 50 is used, good agreement is reached with the expected exit age, the age at which the person stops working, of 63.6 years. It should be noted that the Pensions Agency's definition of the exit age is also based on the limit of age 50 .
The old-age pension benefits considered are incomebased pension (inkomstpension)/ supplementary pension (tilläggspension), guarantee pension (garantipension) and, as mentioned in two of the definitions, sickness compensation (sjukersättning). People who collect only premium pensions are not regarded as pension beneficiaries in the calculations. In these cases, an individual's pension age is defined as the age at which he or she is granted sickness compensation or begins collecting old-age pension and had not previously received sickness compensation. Individuals who collect only occupational or private pension benefits are not included in the measure.

It should be emphasized that the various measures of average pension age do not measure the time at which individuals stop working. It is, for example, permitted to collect a full old-age pension while continuing to work.

If we proceed from the definition based on the average age for collecting old-age pension, it has remained stable in recent years. However, underlying this stable level, there is a wider spread with regard to early and late collection. The picture is completely different if we instead study the exit age, the age an individual exits the labor market. Figure 4 from the Pensions Agency shows substantial change over time.

The figure shows the average age at which gainfully employed persons stop working, provided that they belong to the labor force at age 50. The exit age for men was 65 in 1970. This was followed by a long period of steady decline until the early 1990s, when the level was around 


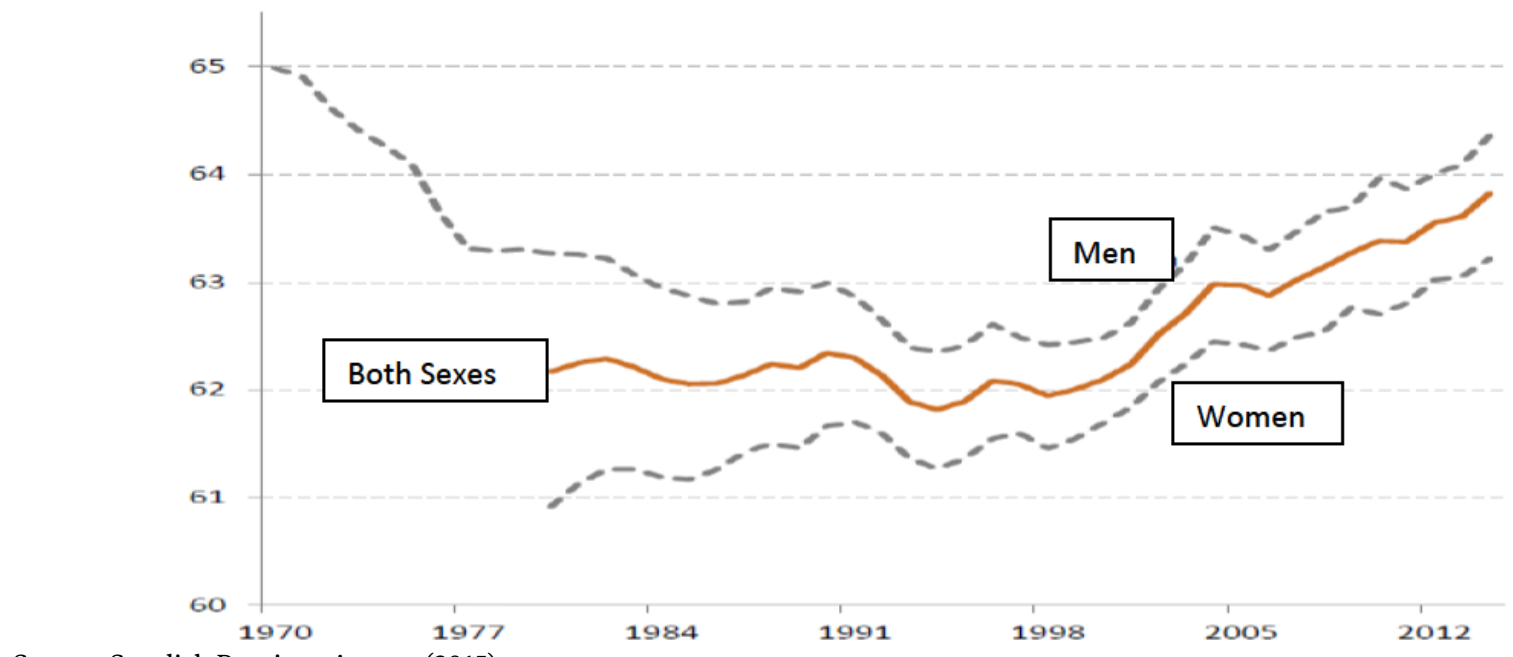

Source: Swedish Pensions Agency (2015)

Figure 4: Changes in exit age over time.

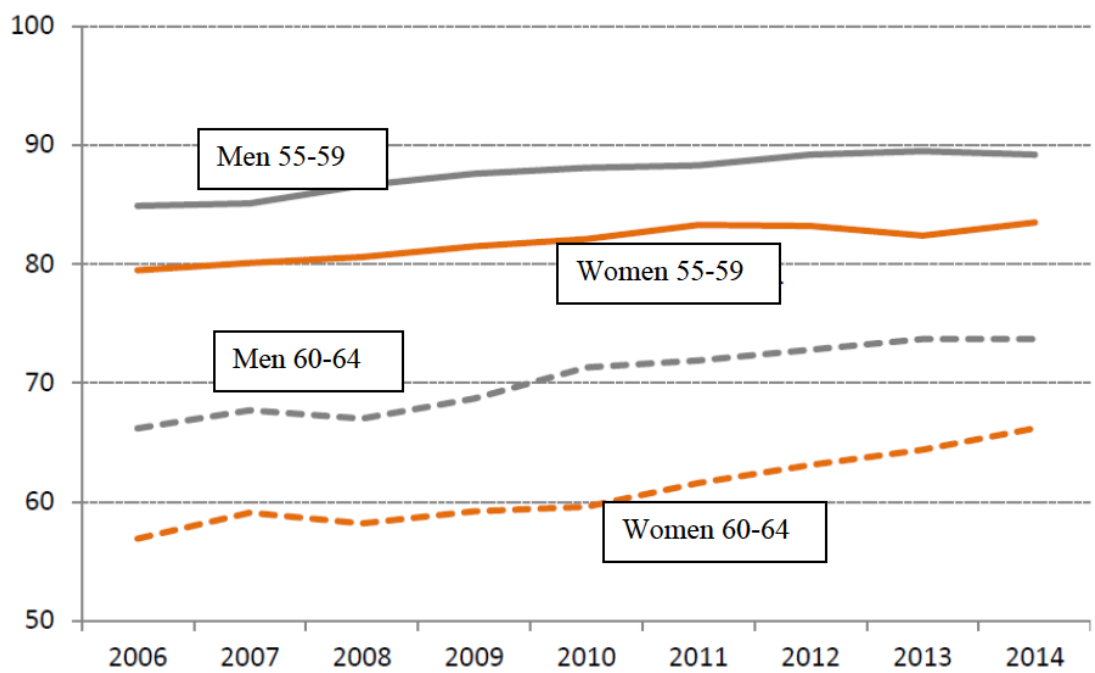

Source: Swedish Pensions Agency (2015)

Figure 5: Labor force participation as a percentage of the population, age 55-64.

age 62.5. After a brief period at this level, the exit age rose to about age 64.5 in 2014, the highest level measured since 1970.

The trend has been similar for women since the early 1990 s, but the level has been about one year lower.

The rise we have observed in the exit age entails a relatively steep increase in labor force participation among older workers. The increase has been ongoing for a long period; see Figures 5 and 6 . There are a number of explanations for this increase, such as the reformed pension system and its rules, for instance, that pension rights are fully earned in the reformed system after age 65 , the increased JSA, and reduced payroll taxes after age 65 . Moreover, the 2003 rise in the "mandatory retirement age" from 65 to 67 under the Employment Protection Act seems to have had some impact. These changes should, however, have contributed mainly to the increases in the 65-69 age range and hardly at all to those aged 70-74. With respect to the increase of the oldest workers, it is interesting to refer back to the particularly favorable conditions with eliminated payroll tax, which drastically reduces employment costs for these individuals.

It should be noted that working hours for those older than 64 are considerably shorter than among younger people. Table 1 presents working hours in 2014 according to the Pensions Agency.

Note that working hours have been taken into account in the previously shown calculations of labor force participation. An individual who works half the normal working hours (20 hours/week) is thus counted as one half of a 


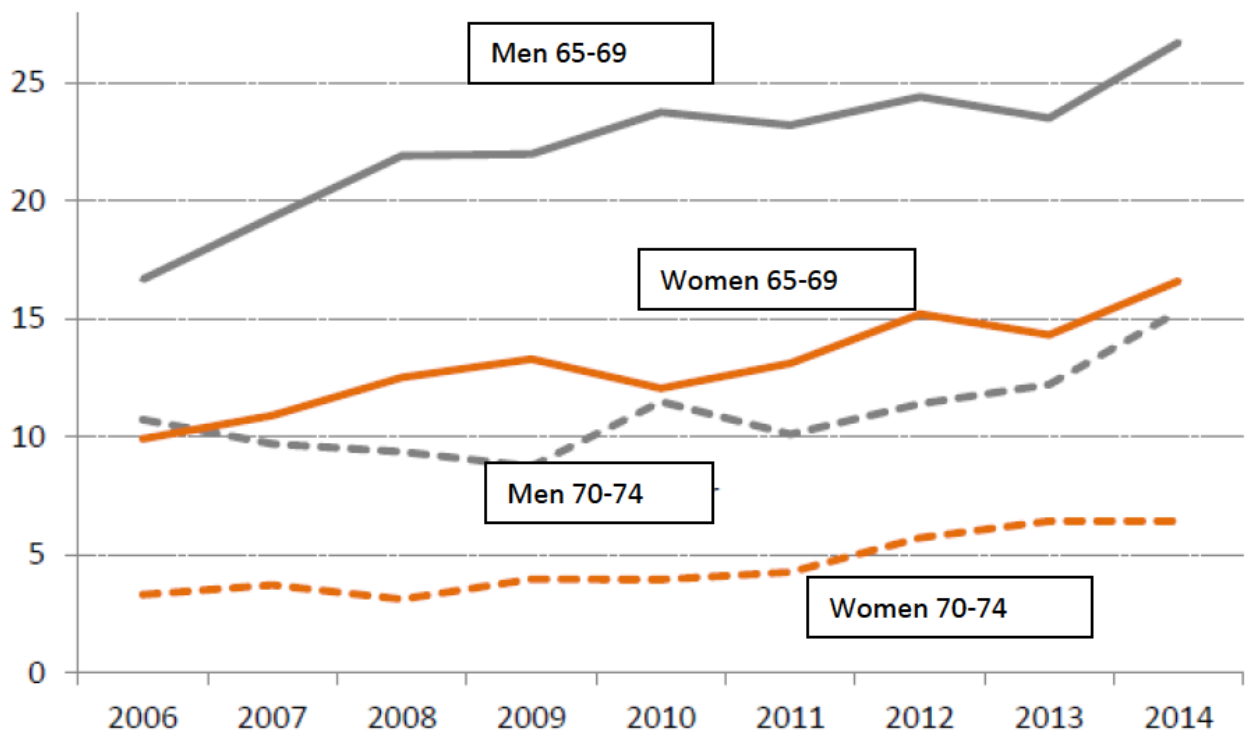

Source: Swedish Pensions Agency (2015)

Figure 6: Labor force participation as a percentage of the population, age 65-74.

Table 1: Working hours/week, 2014.

\begin{tabular}{lcl}
\hline & Women & Men \\
\hline $55-64$ & 36.1 & 40.0 \\
$65-69$ & 24.3 & 28.1 \\
$70-74$ & 13.8 & 21.3 \\
\hline
\end{tabular}

Source: Swedish Pensions Agency (2015)

labor force participant, etc. This adjustment naturally reduces the labor force participation rate.

\subsection{Labor and Pension Income}

It has been clearly shown that exit age and pension age provide two completely different pictures of the dynamics of the pension decision. We argue that the economically relevant measure is associated with the exit age, that is, with labor force participation. The intention is to shed light on this, and particularly how the combination of pension and labor income has developed.

As mentioned, a number of reforms were instituted in 2007 that entailed greater financial incentives for older workers to work. It is therefore interesting to study closely related changes in labor income. Figure 7 shows a relatively large difference in the percentage of older workers with labor income. Across the entire age range of $61-74$, the percentage with labor income in 2011 is higher than the corresponding percentage in 2006, sometimes substan- tially higher. For example, the percentage of people age 66 with labor income has increased by about 10 percentage points. ${ }^{4}$

This does not necessarily mean that the reforms implemented in 2007 explain this increase in labor force participation. We have already mentioned that the new pension system provided greater incentives to continue working in exchange for a higher pension in the future. Employer attitudes towards hiring older workers may also have changed. There are, of course, several causes that determine the changes in working hours observed over time. For many employees, at least short-term, it may be difficult to adjust their preferred working hours. For the individual who is employed and wants to increase their labor income through longer working hours, the decision is not up to the individual alone, but is also controlled by the employer's preferences. One possibility is then to start and run a business instead of or alongside employment. The personal flexibility concerning choice of working hours is greater for the self-employed and it is reasonable to assume that these individuals are more likely to be influenced by financial incentives. This applies both to the decision to start a business as well as the choice of working hours. This

4 It should also be mentioned here that the percentage of older people who work has continued to rise since 2011. According to SCB's LFS statistics, the employment rate in 2012 was 14.9 percent for the 65-74 age stratum; the corresponding figure for November 2015 was 17.1 percent. 
Source: Own calculations, LINDA data 2006 and 2011

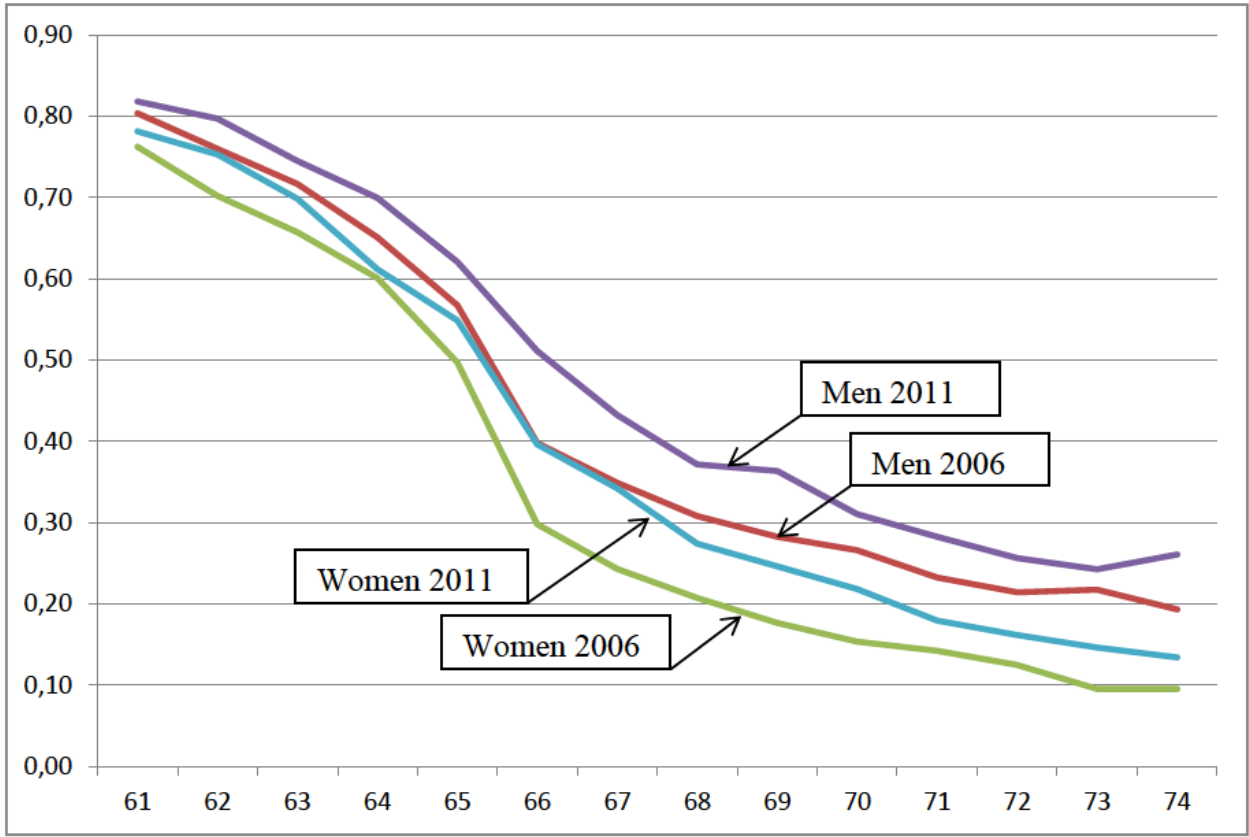

Figure 7: Percentage with labor income, age 61-74, 2006 and 2011.

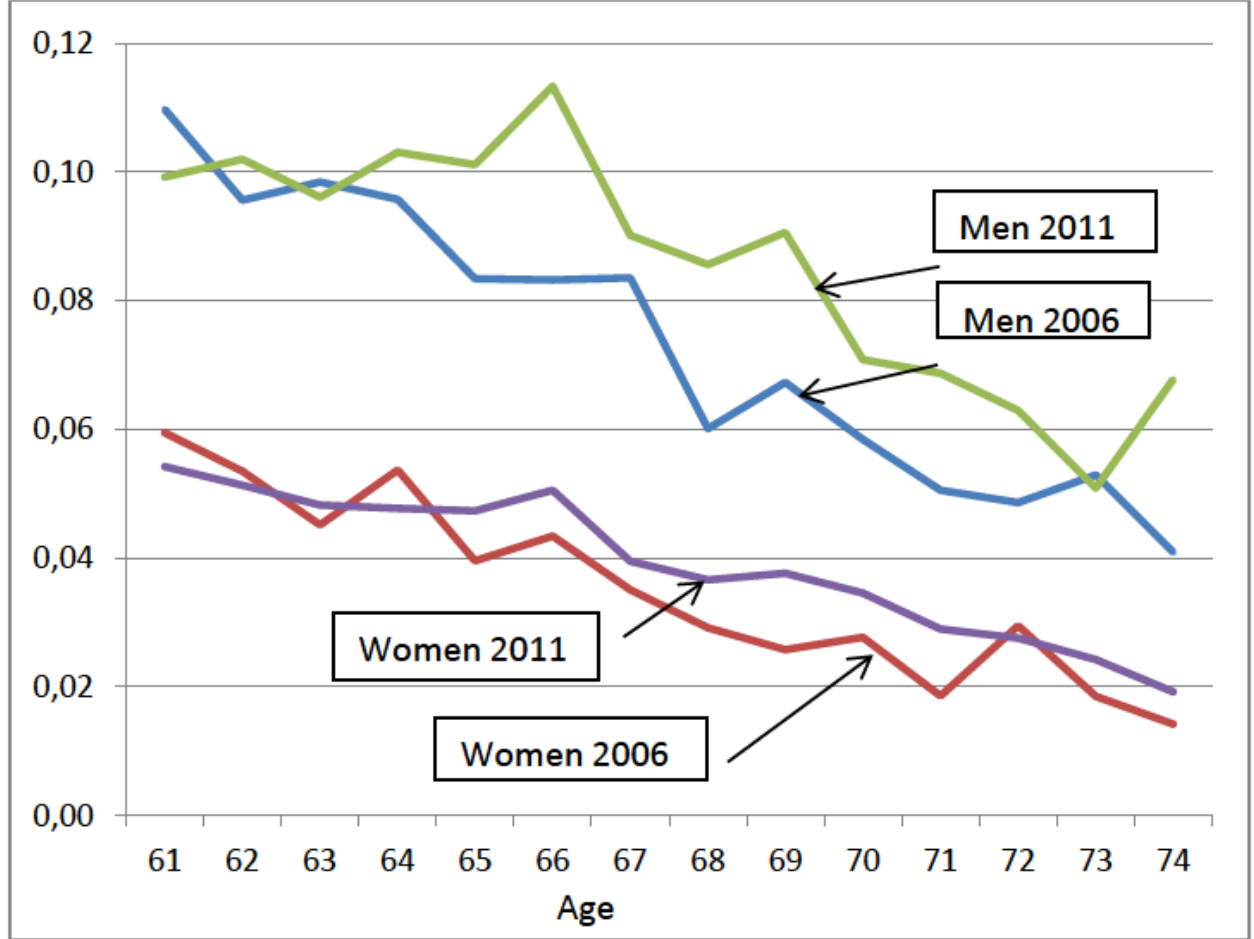

Source: Own calculations, LINDA data 2006 and 2011

Figure 8: Percentage with business income, individuals age 61-74 in 2006 and 2011.

mechanism is probably especially relevant in relation to older workers' choices of working hours. Therefore, one possible way to isolate the effects on individual decisions is to look at business income.
Figure 8 shows how the percentage of older people with business income has developed over time. As evident, the percentage in 2011 is higher as a rule and some- 


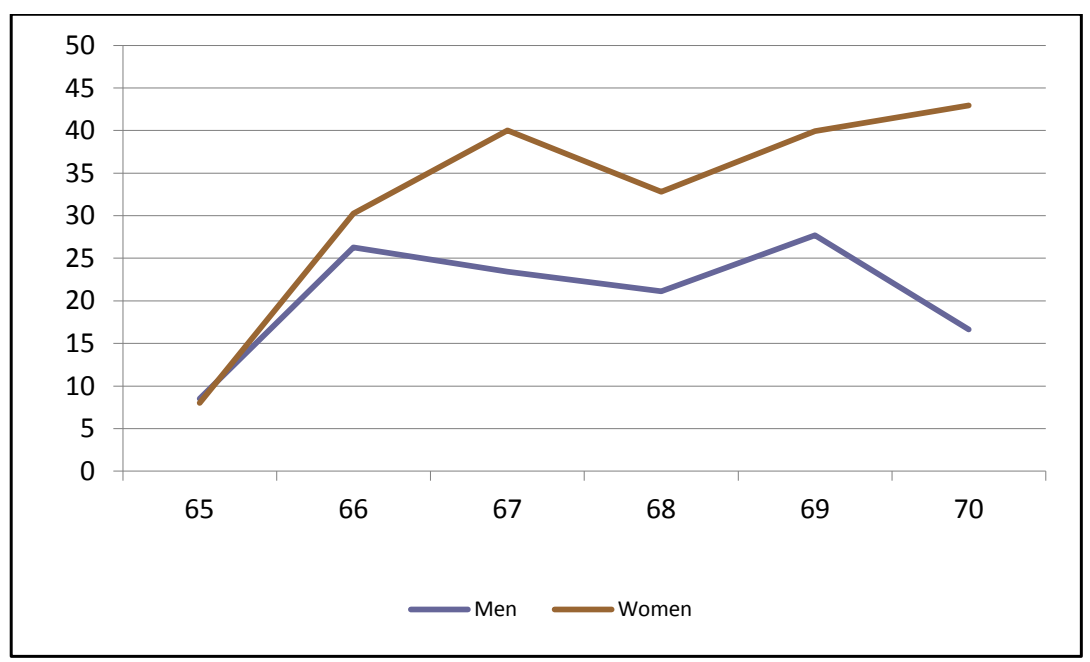

Source: Own calculations, LINDA data 2006 and 2011

Figure 9: Percentage increase from 2006 to 2011 of individuals with both pension and labor income, distributed by age and sex.

times significantly higher than the percentage in 2006, especially for men age 66 .

Finally, it is also interesting to describe the steep rise in the percentage of individuals with both pension and labor income. Figure 9 shows how this percentage has increased since 2006 for various age strata.

The steep increase in the labor supply among older workers entails not only an increase in labor income, but also higher tax revenues and lower public transfers. Total tax revenues on labor income for the 61-70 age stratum have increased by about 30 percent since 2006 (a nominal increase of about SEK 23 billion). Part of this increase can be explained by the increase in the older population (of about 16 percent). The latter is yet another reason to study labor supply and labor income for this group. In 2011, there were more than one million individuals in the 61-70 age stratum and, as we know, this population is going to increase further in the future.

We have confirmed a strong increase in labor income among older workers that has had effects on individual standards of living as well as public finances. One essential question is to what extent this change can be explained by financial incentives, as well as the significance of other factors.

\section{Analysis}

In this chapter, we analyze how tax reforms affect the labor supply for older workers. The introductory section on financial incentives and the design of recent reforms is followed by a description of various methods for evaluating the effects of the reforms. The first method is based on a natural experiment and difference-in-differences analysis. A description and application of more general methods follows. The chapter concludes with an analysis that uses a long-term effects model.

\subsection{Financial Incentives}

Two targeted tax reductions were introduced on 1 January 2007 that applied to people older than 65 . The JSA, implemented for people of all ages, was designed so that it was considerably more generous for people over 65 , while payroll taxes were lowered by about 16 percentage points. In 2009, a higher standard deduction was introduced for people over 65, while the level of the JSA was increased and its structure was simplified.

General payroll taxes were lowered for employees older than 65 so that employers paid only an old-age pension charge (10.21 percent). Employers were not required to pay any payroll taxes for employees born in 1937 or earlier.

While the increased JSA was intended to stimulate the labor supply among older workers, the payroll tax reduction was meant to stimulate demand and compensate for things like productivity downturns or workplace adaptations for older workers. According to the Employment Protection Act, individuals have the right to continue working until age 67.

As the focus of this paper is on the labor supply effects, a more detailed description of the increased JSA is provided. The JSA entailed higher relative profitability of paid work compared to pension income, but the standard deduction for older workers was simultaneously increased. 


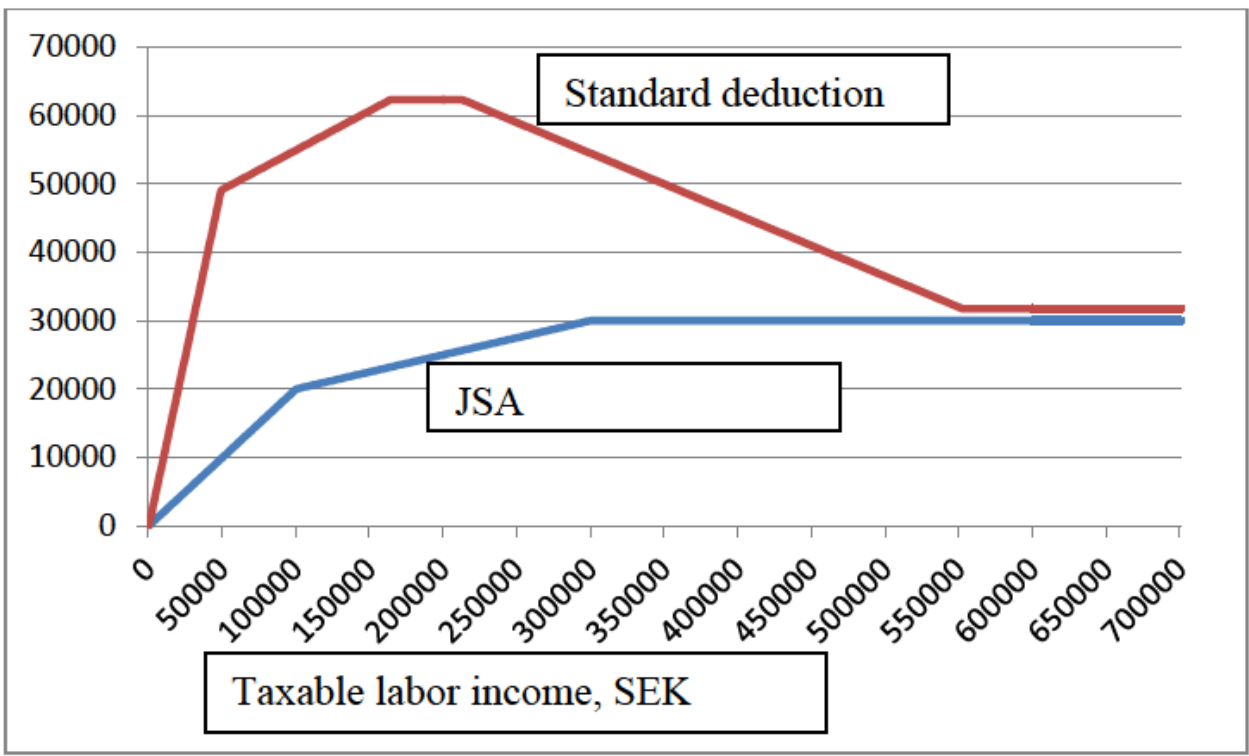

Source: Own calculations

Note: The calculations are based on an average municipal tax of $31.86 \%$

Figure 10: Standard deduction and JSA for individuals older than 65 in 2014.

In addition, effective 2009, people over the age of 65 also receive a higher standard deduction than other earners by means of a special supplement. This "increased standard deduction" has been raised on several occasions. The standard deduction for people over 65 was a maximum of SEK 62,300 in 2014; see Figure 10.

Figure 10 illustrates the profile for the standard deduction and the JSA. It may look like the standard deduction is more generous than the JSA, but this is not the case, as the standard deduction reduces taxable income, while the JSA reduces the tax.

Because, unlike the standard deduction, the JSA applies only to labor income, this entails a substantial increase in the profitability of work. This is an important difference: the standard deduction has only an income effect, which entails a potential negative effect on the labor supply of older workers. This effect is counterbalanced by the generous JSA, which creates incentives for an increased labor supply. The JSA captures the efficiency dimension and the standard deduction the distribution dimension. The substantial impact of the JSA is illustrated by Figure 11, which shows both marginal and average tax rates, with and without the JSA. The figure describes the tax on either only labor income or only transfer income, such as a pension. The picture is more complex for mixed incomes; see further below.

The effect of the JSA is greatest for lower income. For example, annual pension income of SEK 170,000 entails average tax of 20 percent, while the corresponding tax on labor income is only 7 percent. ${ }^{5}$ This difference narrows as income rises, but as shown in the figure, the difference is relatively large in connection with high incomes as well. It should also be noted that this comparison becomes more complicated in connection with mixed incomes, the theme of this paper. The principle remains simple: the JSA means that labor income is taxed at a lower rate than pension income. However, the combined tax profile becomes more complicated and its appearance varies depending upon how much of the income is derived from each income class.

In summary, it can be said that both the increased JSA and lower general payroll taxes for older workers create strong financial incentives to work after the age of 65 . There is obviously an interesting opportunity here to evaluate whether this has also increased the labor supply. This is analyzed using various methods and discussed in more detail in the next section.

\subsection{Evaluation of Tax Reductions for Older Workers}

This section first describes the evaluations of the targeted tax reductions for older workers that have already been implemented, following by a further evaluation of these

5 Note that we have not included general payroll taxes in these calculations. 


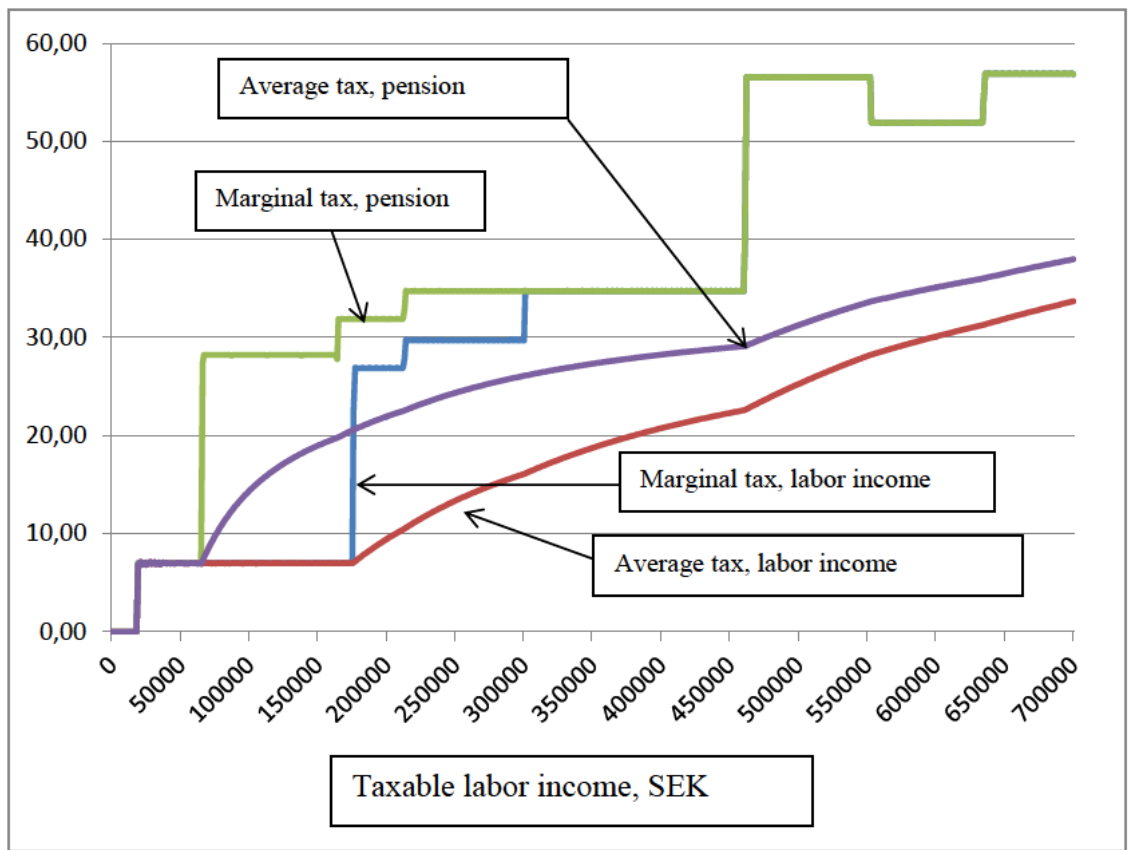

Source: Own calculations

Note: The calculations are based on an average municipal tax of $31.86 \%$

Figure 11: Average and marginal tax in 2014, expressed in percent, for people older than 65 with and without the JSA.

reforms based on more recent data. A concluding section summarizes and attempts to explain the reasons behind the differences in the results.

\subsubsection{Earlier Evaluations}

We know of three reports that have studied the employment effect of targeted tax reductions for older workers. All studies have viewed the tax reductions in 2007 as a natural experiment and used a "difference-in-differences" (DiD) method to identify causal effects. The fact that the reform only applies to people aged 65 or older before the beginning of the tax year was utilized in the calculation; that is, the age allows a division of a control group (younger than 65) and a treatment group (65 or older). The DiD method is based on a comparison of the control and treatment groups before and after a reform.

The ability to base the definition of the control and treatment groups on the age of the individual is advantageous. This is an exogenous factor that cannot be affected by the individual. One consideration in the definition of the control and treatment groups is how restrictive an age division should be used. In theory, the control group may be defined as those who become 65 the first day in January in a particular year (year $t$ ). These individuals will not benefit from the increased JSA that year (year $t$ ). The treatment group may be defined as those who become 65 the last day in December in the year before (year $\mathrm{t}-\mathrm{l}$ ), who will receive the increased JSA during the following year (year $t$ ). This division is ideal in the sense that the individuals in the control and treatment groups are almost the same age (differing by only one day), and thus the age effect is minimal. If they are also alike in all other respects, the conditions exist to interpret any differences in employment and working hours as causal, that is, caused by the reform. In practice, such a restrictive definition is impossible because the sample used for the analysis would be too small. A wider age range has therefore been used. The evaluations reported in the following were based on a less restrictive definition and sometimes a more restrictive definition based on birth month or birth quarter.

One criticism of the simplest form of DiD is that there is no control of the effect of other factors that may be significant. A more general calculation of the $\mathrm{DiD}$ estimator is based on a regression analysis, which makes it easy to include any effects of background variables relevant to the individual. All results reported were based on the general method for estimating the magnitude of the reform effect. This model can then be written

$$
\begin{aligned}
y_{i t} & =\beta_{0}+\beta_{1} p_{i}+\beta_{2} t_{i}+\beta_{3} p_{i} t_{i}+\gamma_{1} x_{1 i t} \\
& +\gamma_{2} x_{2 i t}+\ldots+\gamma_{k} x_{k i t}+\varepsilon_{i t}
\end{aligned}
$$


where $y_{i t}$ is the value of the outcome variable (such as employment, that is, whether or not the person works) for the individual in year $\mathrm{t}, p_{i}$ is an indicator of the period before $(p=0)$ or after $(p=1)$ the reform, $t_{i}$ is an indicator of the control group $(t=0)$ or treatment group $(t=1)$. The interaction between the $t$ and $p$ variables yields the reform effect $\beta_{3}$. The $x$ variables describe other relevant factors that may affect the outcome. The parameters are designated $\gamma_{1}-\gamma_{k}, \varepsilon$ is a random term, and $\mathrm{k}$ states the number of control variables.

For $\beta_{3}$ to identify the effects of the tax reduction for older workers, there must be no other contemporaneous events or reforms (that cannot be controlled for) that affect the control and treatment groups in different ways. As mentioned, the increased standard deduction for older workers was implemented in 2009. The increased standard deduction also targets the same group that receives the increased JSA. There is therefore a risk that this reform will also affect the estimates. The effect of the latter reform, however, may be assumed negligible because this tax reduction does not distinguish labor income from other income (pension). It is likely that the increased standard deduction may have a negative effect on the employment rate due to the "income effect", which means that the isolated effect of the JSA may be stronger than the measured effects (which also include the possible counter-effect of the standard deduction).

The first report, by Pirttilä and Selin (2011), compares employment rates in the Labor Force Surveys (LFS) for the age strata 65-74 and 55-64, before and after the reform in 2007. They find an employment rate increase of 2 percentage points. This may seem low, but actually means that after the reform, the employment rate increase for the treatment group was about 19 percent higher than for those in the treatment group before the reform. ${ }^{6}$

The second report is a comprehensive evaluation of the JSA reported in Ministry of Finance (2012). A (minor) part of the evaluation refers to the JSA for older workers. The analysis compares the labor market outcome based on two different definitions of the control and treatment groups. The first comparison is among persons who are either 66 or 64 years old. The second comparison refers to individuals whose $65^{\text {th }}$ birthdays occur either in the last quarter of one year or the first quarter of the next. As mentioned earlier, the latter group division yields control and treatment groups with a smaller age difference but also a significantly smaller sample. ${ }^{7}$

A reform effect of 7 percentage points is obtained in the comparison between the groups age 66 and age 64 . The Ministry of Finance report explains the size of this effect in relation to the reduction in the probability of being in work that occurs between age 64 and age 66 . The reform effect of 7 percentage points diminishes this reduction by 20 percent, which is considered as a large effect in the report. The comparison based on birth quarter yielded no statistically significant results. One explanation for this may be that the more restrictive definitions of the control and treatment groups resulted, as mentioned, in a considerably smaller sample. In addition to reporting the effect on the probability of working, results are also reported regarding working hours. No statistically significant results are reported for working hours.

It is important to note that the reform evaluated by the Ministry of Finance covers the JSA, the standard deduction, and payroll taxes. Because the higher standard deduction was implemented in 2009, it is possible to control for this reform by basing the analysis on a period that includes 2009 and comparing it with the effect when 2009 is not included. This is done in the report and as no significant differences were found, the conclusion is that the results are not explained by the standard deduction. However, as it is not possible to perform a similar control for reduced payroll taxes, the reform effect should be interpreted as an effect of both reforms: the increased JSA and reduced payroll taxes. Naturally, this also applies to the results reported in Pirttilä and Selin (2011).

The third report, written by Laun (2012), is perhaps the most ambitious. Laun uses a considerably larger sample (the entire population) and devotes greater attention to testing to ensure that statistical conditions are met. The sample consists of individuals who turned 65 from November to February between 2001 and 2009 and had taxable income in at least one of the three to five preceding years. This is thus an example of a relatively restrictive definition of the control and treatment groups. The treatment group turned 65 in the period of November-December in year $\mathrm{t}-1$ and the control group during January-February in year $t$. The choice of this restrictive age definition is justified on

6 We will return to the interpretation of the results of these evaluations, but note that Pirttilä and Selin choose to present the reform effect in relation to the average employment rate for the treatment group before the reform.
7 Only about 500 individuals are included in the Ministry of Finance's analysis, based upon the more restrictive age definition. 
the basis of the results of a statistical test. ${ }^{8}$ The choice that individuals must have had taxable income in at least one of the three to five years before 2001 is based on the premise that only individuals who have the potential to be affected by the reform should be included in the sample. The idea is that individuals who have not previously had a stable connection to the labor market are highly unlikely to be affected by the reform.

In addition to the employment effect, the outcome variables include taxable income, percentage of previous labor income, and number of remunerated months. The results show that during the year immediately following the $65^{\text {th }}$ birthday, employment increased in the treatment group by 1.5 percentage points, annual earnings as a share of previous earnings increased by 1.8 percentage points, and the number of remunerated months increased by 0.13 . These effects are significantly different from zero, but the effect on annual earnings in SEK cannot be significantly differentiated from zero. These effects apply primarily to men and are especially large for the self-employed. As usual, interpretation is facilitated if these effects are put in relation to an appropriate base. Laun chooses to relate them to the average in the sample for each outcome variable. This implies an increase in employment of 4.9 percent, corresponding to an increase of 7.6 percent in taxable labor income as a share of previous earnings, and an increase of 2.9 percent in the number of remunerated months.

Laun also performs a public finance calculation, which shows that the reforms are far from being selffinanced when both the payroll tax reduction and the JSA are taken into account. However, this changes when only the effect of the JSA is considered, which increases the degree of self-financing to 70 percent. Notably, the degree of self-financing for the sub-sample of men only is 120 percent. It should be noted that the mechanical tax cost (disregarding behavioral effects) for the reduced payroll tax is considerably larger than the equivalent for the JSA.

\subsubsection{Calculations Based on More Recent Data}

A further evaluation is performed in this paper to verify the three earlier studies using more recent data obtained from LINDA. We proceed from two outcome variables: the

$\mathbf{8}$ According to the test, a restrictive age division based only on December-January is rejected, but a division based on NovemberFebruary or October-March cannot be rejected. It is thus not the case that a more restrictive division is necessarily preferable. occurrence of labor income over one income base amount and the occurrence of business income above one quarter of one income base amount. Note that the latter income is included in the former.

The reason for studying the self-employed group is that this yields a sample in which the decision to continue working depends substantially upon personal choice. There is greater flexibility among the self-employed and income from such activities may be regarded as a supplement to pension income. Another reason to study the selfemployed is that this creates an opportunity to interpret which effect, the JSA or the payroll tax reduction (social security contributions paid by the self-employed) is most significant. For the self-employed, it is reasonable to regard the payroll tax cut in the same way as the increased JSA. There is thus an opportunity here to calculate the portion of the reform effect that is due solely to the increased JSA.

Before the estimates of the parameters in the model described above are reported, it is interesting to illustrate how the control and treatment groups differ in order to gain an understanding of the quality of the results subsequently reported. ${ }^{9}$ The less the characteristics of the two groups differ, the better, as this indicates that the groups are alike in ways other than how they are affected differently by the reforms. Table 2 presents descriptive characteristics for the 64 and 66-year-olds included in the sample. Notably, a more restrictive age definition in which birth quarter information was used was also tested. This definition yielded similar results, but lower precision. For that reason, the results are presented in Tables 2 and 3 only for individuals age 64 and 66 . The results for the more restrictive age definition are, however, presented in Table 4.

Apart from the outcome variables, the differences between the two groups are relatively small. This is as expected and aligns well with the reports by the Ministry of Finance and Laun.

The next step is to estimate the parameters in the model (1) with the background variables included in Table 2. The results are shown in Table 3.

As evident in Table 3, the reform effect is positive and estimated with high precision. Also as indicated by the last row in Table 3, this result holds regardless of the inclusion of control variables. For the occurrence of annual income above one income base amount it is 3.1 percentage points. The corresponding figure for business income is 1.1

9 It is not a problem if the variables differ between the control and treatment groups because these differences are controlled for in the regression, but the variables must not change at the same time the reforms were implemented. 
Table 2: Statistics for individuals aged 64 and 66 (2004-2011).

\begin{tabular}{|c|c|c|}
\hline & 64 & 66 \\
\hline $\begin{array}{l}\text { Percentage with annual income } \\
\text { above one income base amount }\end{array}$ & 0.53 & 0.22 \\
\hline $\begin{array}{l}\text { Percentage with business income } \\
\text { above } 25 \% \text { of one income base } \\
\text { amount }\end{array}$ & 0.06 & 0.05 \\
\hline $\begin{array}{l}\text { Percentage highest education } \\
\text { compulsory school }\end{array}$ & 0.31 & 0.34 \\
\hline $\begin{array}{l}\text { Percentage highest education sec- } \\
\text { ondary school }\end{array}$ & 0.52 & 0.51 \\
\hline $\begin{array}{l}\text { Percentage highest education uni- } \\
\text { versity }\end{array}$ & 0.16 & 0.15 \\
\hline Percentage married & 0.76 & 0.75 \\
\hline Percentage male & 0.53 & 0.55 \\
\hline Percentage foreign-born & 0.12 & 0.12 \\
\hline Percentage self-employed & 0.08 & 0.08 \\
\hline Percentage residing in a large city & 0.31 & 0.31 \\
\hline $\begin{array}{l}\text { Percentage residing in a medium- } \\
\text { sized city }\end{array}$ & 0.40 & 0.40 \\
\hline Percentage residing in rural area & 0.29 & 0.30 \\
\hline $\begin{array}{l}\text { Number of individuals in the sam- } \\
\text { ple }\end{array}$ & 47,342 & 41,381 \\
\hline
\end{tabular}

percentage points. As usual, these effects are easier to interpret if they are related to an appropriate base. If the effect is presented in relation to the mean for the entire sample (that is, both before and after the reform) 38.7 percent, the result is an increase of 8.1 percent in the percentage of people with labor income. The corresponding increase for business income is 18.6 percent. The reform effect can also be related to the mean for the treatment group before the reform. This yields a more natural comparison because it refers to the same age stratum and the only difference is that the mean refers to the period before the reform. Such a calculation returns a reform effect of 18.9 percent for labor income and 24.1 percent for business income. In sum, the results indicate that the reforms providing targeted tax reductions for older workers have had a strong effect on employment.

\subsubsection{Summary of Evaluations Based on Difference-in-Differences Methods}

A comparison of all evaluations was presented in Table 4 in order to compare the results shown in Table 3 with the aforementioned evaluations. The comparison refers only to the effect on the employment rate, and in cases where different definitions were used for the control and treatment groups, only those results appears to be the main result in each study is presented.

Even though these evaluations refer to the same reforms and similar time periods, there are large differences in the calculated percentage effects. Evaluation at the mean for the entire sample results in a range of 3-18 percent, while the corresponding range for evaluation at the mean for the treatment group is $8-47$ percent. There may be several reasons for this wide spread; one apparent reason is the uncertainty arising from different data sources and thus different sample sizes. The analysis in Pirttilä and Selin is based on monthly LFS data and the total sample size is thus 240 observations (10 years, 12 months, and 2 groups). The sample size in Laun is around 180,000 individuals.

The evaluation that shows the greatest reform effect is found in the Ministry of Finance report. An explanation for this is shown in Table 5. The Ministry of Finance's analysis is based on a nonlinear probit model, while the other reports are based on linear models estimated with OLS. Aimed at replicating the results presented in the Ministry of Finance report, we estimate a probit model for the same time period, 2004-2009, and compare these results with the corresponding results based on the linear model estimated with OLS. As evident, the probit results in Table 5 are similar to those shown in Table 4 (0.06 instead of 0.07). ${ }^{10}$ The comparison of the results based on OLS shows a substantial difference, as the probit results are more than twice as large. ${ }^{11}$

10 The Ministry of Finance report states that the effect was evaluated at the means of the $\mathrm{x}$ variables. Accordingly, the same method is used here. This is, however, not correct; the effect should instead be evaluated for each individual value of the $\mathrm{x}$ variables, after which the mean can be calculated across all individuals. In our case, these two approaches do not yield any significant differences (calculated as the mean for all individuals, the marginal effect is 0.05 ). It should also be observed that the reform effect is not a continuous variable but a discrete variable (takes only the values of 0 or 1 ). This should be considered when the reform effect is calculated. In this application, however, it has little effect, which is why the results reported here are calculated as if the reform effect were continuous. See Puhani (2012) for a discussion of the interpretation of results when a probit model is used in a DiD analysis.

11 This does not necessarily mean the probit results are wrong; it is instead the case that the Ministry of Finance does not explain in its report why they chose to base the analysis on this model. Despite all, the linear model estimated with OLS is the method customarily used according to the DiD literature. It is also difficult to understand the large difference in the probit and OLS results and further analysis would be required to explain this. 
Table 3: Estimated parameters.

\begin{tabular}{|c|c|c|}
\hline & $\begin{array}{c}\text { Annual income } \\
\text { above one income } \\
\text { base amount }\end{array}$ & $\begin{array}{l}\text { Business income } \\
\text { above } 0.25^{\star} \text { of one } \\
\text { income base } \\
\text { amount }\end{array}$ \\
\hline Constant & $0.4371^{\star \star \star}$ & $0.0301^{\star \star \star}$ \\
\hline $\mathrm{p}$ (before reform $=0$, otherwise 1 ) & $0.0765^{\star \star \star}$ & $0.0122^{\star \star \star}$ \\
\hline $\mathrm{t}($ Age $66=1$, otherwise 0$)$ & $-0.3283^{\star \star \star}$ & $-0.0143^{\star \star \star}$ \\
\hline Reform $(p \times t)$ & $0.0313^{\star \star \star}$ & $0.0106^{\star \star \star}$ \\
\hline Highest education secondary school & $0.0412^{\star \star \star}$ & -0.0034 \\
\hline Highest education university & $0.1615^{\star \star \star}$ & $0.0098^{\star \star \star}$ \\
\hline Married & $-0.0316^{\star \star \star}$ & $0.0067^{\star \star \star}$ \\
\hline Male & $-0.0140^{\star}$ & $0.0301^{\star \star \star}$ \\
\hline Married and male & $0.1103^{\star \star \star}$ & $0.0175^{\star \star \star}$ \\
\hline Foreign-born & $-0.1168^{\star \star \star}$ & $-0.0249^{\star \star \star}$ \\
\hline Self-employed & $0.2883^{\star \star \star}$ & -- \\
\hline Self-employed and foreign-born & $0.0874^{\star \star \star}$ & -- \\
\hline Medium-sized city & $-0.320^{\star \star \star}$ & $-0.0048^{\star \star}$ \\
\hline Rural & $-0.0364^{\star \star \star}$ & $0.0049^{\star}$ \\
\hline Mean for percentage with income in the entire sample & 0.387 & 0.057 \\
\hline Mean for percentage with income in the treatment group before the reform & 0.166 & 0.044 \\
\hline The estimated reform effect without control variables & $0.0382^{\star \star \star}$ & $0.0117^{\star \star \star}$ \\
\hline
\end{tabular}

Note: ${ }^{\star}$ denotes significance at $10 \%,{ }^{\star \star}$ significance at $5 \%$ and ${ }^{\star \star \star}$ significance at $1 \%$. The standard errors are robust to heteroscedasticity. In addition to the variables shown here, the calendar year, from 2005-2010, is included in the model.

As mentioned, the evaluation in Laun (2012) is very ambitious, and as it has also garnered a great deal of attention, it may be justified to more closely examine these results. Two results are presented in Table 5 that attempt to imitate the method used by Laun. The same time period, 2001-2009, and the same selection are used; that is, the sample is based only on individuals who had income during a five-year period before 2001. The results in which the control group consists of individuals age 64 and the treatment group consists of those who are age 66 are presented first. Laun does not use this definition of the control and treatment groups; this is done as a comparison to earlier results. As shown, a lower reform effect is now obtained and thus lower percentage effects. These differences are mainly explained by that the period ends in 2009 instead of 2011, as before.

The second comparison is based on a definition of the control and treatment groups similar to that used by Laun. The only difference is that the definition in Table 5 is based on quarterly data, rather than monthly data. The results are similar to those based on 64 and 66-year-olds. Thus, the definition of the control and treatment groups is not particularly important. The results are also reasonably similar to those presented in Laun (0.024 compared with
0.015), but the precision is not as high, which can probably be explained by the smaller sample resulting from the more restrictive definition of the control and treatment groups.

To sum up this attempt to explain the differences in the results presented here, we can confirm that the choices of model and time period make a difference. The large effects presented by the Ministry of Finance are explained primarily by the choice of model. The explanation of why the effects reported in this paper are greater than those found in the report by Laun is that our results are based on more recent data.

A question discussed in the two earlier reports is how much time before and after a person turns 65 should be selected when the control and treatment groups are defined. One problem with restricting the age range is that the sample shrinks. Here, the analysis in the report by Laun has an advantage because it is based on a larger sample, the entire population, and there is also information about the individual's birth month. The information to which we have access in LINDA allows a division only into birth quarters. As shown in Table 4, the results of this paper do not indicate any significant differences when birth quarter or birth 
Table 4: Summary of evaluations of effects on the employment rate of targeted tax reductions for older workers.

\begin{tabular}{|c|c|c|c|}
\hline & $\begin{array}{l}\text { Reform effect } \\
\text { Estimated } \\
\text { parameter }\end{array}$ & $\begin{array}{l}\text { Percentage effect in } \\
\text { relation to mean, } \\
\text { entire sample }\end{array}$ & $\begin{array}{l}\text { Percentage effect in } \\
\text { relation to mean, } \\
\text { treatment group } \\
\text { before the reform }\end{array}$ \\
\hline Pirttilä and Selin (2011) & 0.020 & 3 & 19 \\
\hline \multicolumn{4}{|l|}{ Data: LFS, 2001-2010 } \\
\hline \multicolumn{4}{|l|}{ Control: 55-64, Treatment: $65-74$} \\
\hline \multicolumn{4}{|l|}{ Mean: } \\
\hline \multicolumn{4}{|l|}{ Entire sample, $60 \%{ }^{*}$} \\
\hline \multicolumn{4}{|l|}{ Treatment group before reform, $10.3 \%$} \\
\hline Ministry of Finance (2012) & 0.07 & 18 & 47 \\
\hline \multicolumn{4}{|l|}{ Data: HF, 2004-2009 } \\
\hline \multicolumn{4}{|l|}{ Control: 64, Treatment: 66} \\
\hline \multicolumn{4}{|l|}{ Probit model } \\
\hline \multicolumn{4}{|l|}{ Mean: } \\
\hline \multicolumn{4}{|l|}{ Entire sample, $38.8 \%{ }^{\star *}$} \\
\hline \multicolumn{4}{|l|}{ Treatment group before reform $15 \%$} \\
\hline Laun (2012) & 0.015 & 5 & 8 \\
\hline \multicolumn{4}{|l|}{ Data: Total population, 2001-2009 } \\
\hline \multicolumn{4}{|l|}{ Control: Aged 65 Jan-Feb } \\
\hline \multicolumn{4}{|l|}{ Treatment: Aged 65 Nov-Dec } \\
\hline \multicolumn{4}{|l|}{ Only individuals with income $1996-2000$} \\
\hline \multicolumn{4}{|l|}{ Mean: } \\
\hline \multicolumn{4}{|l|}{ Entire sample $30.6 \%$} \\
\hline \multicolumn{4}{|l|}{ Treatment group before reform $19,3 \%^{\star \star \star \star}$} \\
\hline Flood (2016) & 0.031 & 8 & 19 \\
\hline \multicolumn{4}{|l|}{ Data: LINDA, 2004-2011 } \\
\hline \multicolumn{4}{|l|}{ Control: 64, Treatment: 66} \\
\hline \multicolumn{4}{|l|}{ Mean: } \\
\hline \multicolumn{4}{|l|}{ Entire sample $38.7 \%$} \\
\hline \multicolumn{4}{|l|}{ Treatment group before reform $16.6 \%$} \\
\hline Flood (2016) & 0.022 & 7 & 13 \\
\hline & (Significant at $10 \%$ ) & & \\
\hline \multicolumn{4}{|l|}{ Control: Aged 65, Jan-Mar } \\
\hline \multicolumn{4}{|l|}{ Treatment: Aged 65, Oct-Dec } \\
\hline \multicolumn{4}{|l|}{ Mean: } \\
\hline Entire sample $31.4 \%$ & & & \\
\hline Treatment group before reform $16.2 \%$ & & & \\
\hline Flood (2016) & 0.011 & 19 & 24 \\
\hline Data: LINDA 2004-2011 & & & \\
\hline Self-employed & & & \\
\hline Control: 64 , Treatment: 66 & & & \\
\hline Mean: & & & \\
\hline Entire sample $5.7 \%$ & & & \\
\hline Treatment group before reform $4.4 \%$ & & & \\
\hline
\end{tabular}

${ }^{\star}$ Rough estimate based on Figure A5, ${ }^{\star \star}$ Calculated based on Table $7.1,{ }^{\star \star \star}$ Estimate based on Chart 7.1, ${ }^{\star \star \star \star}$ Calculated based on LINDA data Note: HF (Household Finances) is a sample survey at the individual level that consists of both register-based and interview-based data. The sample size is about 40,000 (about 20,000 households) 


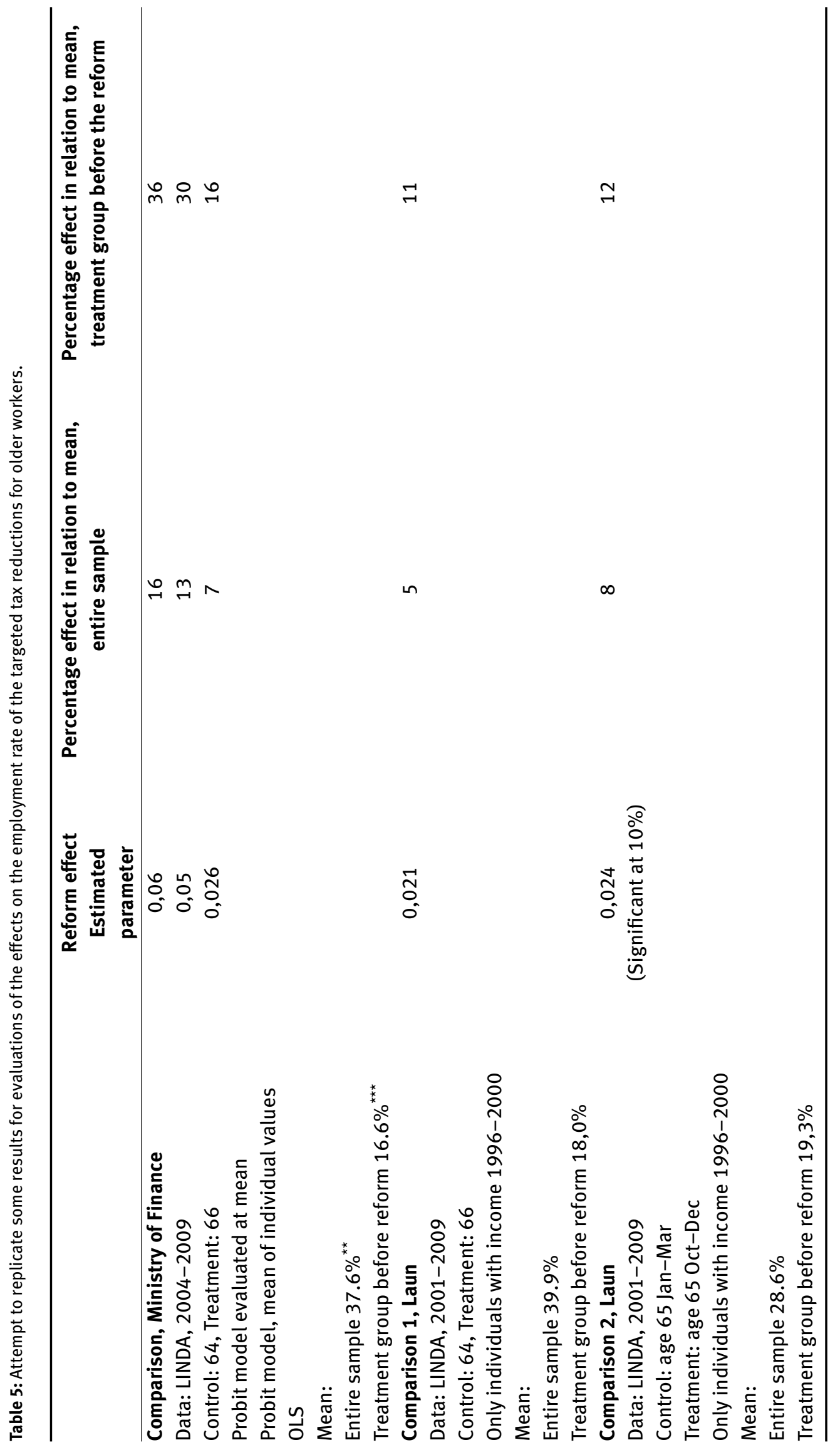


year is used (but precision declines when birth quarter is used).

The ambition to define the control and treatment groups so that they optimally correspond to the assumptions required by the DiD method entails a restrictive definition. This raises the issue of the generalizability of these types of studies. It can be stated here that the results in the report by Laun can only be interpreted as the effect of a comparison between individuals born in NovemberDecember and those born in January-February, provided that they had taxable labor income in at least one of the three to five preceding years. The fundamental idea is that individuals in the control group, who turned 65 immediately after the first of the year, will become eligible for the tax reductions one year later than the treatment group and that this affects their employment rate.

The question can be considered of how the effect of the targeted tax reduction occurs and, especially, how rapidly these effects can be expected. In Appendix 5 of the Ministry of Finance analysis, it is argued that the effects should be swift, since the main effect has to do with whether or not the individual continues to work. This is questionable and the transition from employment to retirement is a complex choice that encompasses numerous dimensions.

As a point of departure, choose two individuals, one of whom turns 65 just before the end of the year and the other just after. The models we have used thus far proceed from the premise that the effect of the reform can be described as the effect that the individual who turns 65 before the end of the year has greater incentive to continue working. This does not have to mean that the person who turns 65 after the end of the year is not affected. It might be so, for example, that this person knows they will receive the increased JSA one year later and continues to work for that reason. In addition to this effect, it might also be that people who have already stopped working may choose to return to work once they have reached the age at which the increased JSA applies.

In addition, any effects are also dependent upon what information the person has about the reform and its effects. One indication supporting that it takes time before reform effects are realized is that more recent data produce larger effects compared to older data. Despite all, the point is that individuals must have the relevant information about the effects of a reform and it probably takes time before this knowledge has spread.

In light of the problems of the generalizability of results based on the DiD method, the reform is analyzed in the next section based on structural models combined with a microsimulation model. In addition to evaluating only the already implemented reform, a hypothetical re- form in which the increased JSA takes effect at age 61 is also evaluated.

\subsection{General Models for Evaluating Economic Reforms}

The evaluation is based on an existing model, SWEtaxben. SWEtaxben can be described as a microsimulation model designed to evaluate how Swedish households are affected by changes in the tax and benefits systems. The distinguishing characteristic of the model is that it takes adjustment effects into account, primarily adjustment in the labor supply. This adjustment occurs via two different mechanisms and is modelled in two different ways: first, models for the probability of being unemployed, on long-term sick leave, on disability pension, and receiving old-age pension, followed by models that describe the change in working hours for those who work. This type of analysis requires access to high-quality databases. This requirement is largely met by the register data (LINDA) used. The sample amounts to almost 8 percent of the population, which provides high precision in the results. Because the sample weights are known, aggregate statistics for the entire population can also be calculated. ${ }^{12} \mathrm{~A}$ problem with earlier versions of SWEtaxben was that combined incomes were not possible. An individual classified as employed could then have only labor income, while an individual classified as retired could have only pension income. As discussed in this paper, this is not a realistic description. For this reason, SWEtaxben has been updated to allow combined income.

The update will be described first in this section and then the modified version of SWEtaxben is used in the next section to evaluate the increased JSA. The results are compared with the earlier DiD results. An advantage of structural models is that hypothetical reforms can also be evaluated. One such hypothetical reform is to implement the increased JSA earlier, at age 61. This reform is also evaluated in the next section.

A natural approach to modeling combined labor and pension income would be to proceed from a labor supply model adjusted to older individuals. Unfortunately, this is not possible because LINDA data does not contain any information about working hours for older workers. For this reason, an alternative model structure has been used that consists of two separate but related decisions. First, a model for the decision to begin collecting old-age pen-

12 See Ericson et al. (2009) for a more detailed description. 
sion and then, assuming that the old-age pension is collected, a model that determines the size of the pension. Based on these two models, the percentage of pension income in relation to the potential income to which the individual is entitled upon full pension is calculated for each individual. If the percentage is one or near one, the individual is presumed a full-time retiree and the predicted labor income is little or zero. If the percentage is low, the predicted labor income is higher. The size of the labor income has been calculated based on the income levels observed in LINDA. Various levels were prepared for every age from 61 to 70 and separately for men and women. When labor income exists, working hours are also predicted, using an observed or predicted hourly wage. ${ }^{13}$ The approach can be briefly described as a model that predicts pension income and then, by means of calibration, calculates labor income and working hours.

The economically interesting variable in the model that describes the individual's choice to collect their oldage pension is the replacement rate. This is defined as a ratio of net of tax income where the numerator is defined as the income if the individual is a full time pensioner (no income from work) and the denominator is the income if the individual is working full time (no income from pension). In these calculations the rules of the tax and pension systems are used as well as the rules of all other individual or household specific benefits. The calculation of pension income is based on all sources of income; public, occupational and private. For the married/cohabitant household the net of tax income is based on the income for the household. For instance the replacement rate for the male is calculated based on the observed income of his spouse and vice versa for the female. The sample consists of individuals age 61-70, with separate models used for men and women. We proceed from a balanced LINDA panel 20092011; that is, all individuals are included in all years.

The dependent variable in the model takes value one if the individual has pension income; otherwise it is equal to zero. The control variables used are age, education, nativeborn, and indicators for the various years included, as well as an indicator for whether the individual has labor income above the cap in the national pension system. The latter is intended to take into account the nonlinear effects of the pension-based income. In addition to nonlinear effects in income, such effects are also presumed for older workers. In order to describe this effect, we assume that age squared is significant, in addition to age. Unfortu-

13 Write labor income as $\mathrm{WH}$, that is, hourly wage multiplied by working hours. When W and WH are known, $\mathrm{H}$ can be calculated. nately we lack information about the individual's health status and health might be an important reason for the retirement decision. It is difficult to speculate about the expected effect of not including any health information but at least we should not expect any important changes in the general level of health during the short period used for estimation (2009-2011). Apart from a trend there might also be important across individual differences in health that could have an effect on the size of the estimated replacement parameter. Since we do not have any information about health in our data this is a problem that we cannot address. However, education is included and since there is a positive correlation between health and level of education this in part controls for the lacking health information.

The model has been estimated as a random effect logit with an initial value (the value of the dependent variable is the year 2009).

The results are presented in Table 6 and, as expected, the estimated parameter for the replacement rate is positive. This means that a reform such as the increased JSA (which entails a lower replacement rate) reduces the probability of collecting income from the old-age pension. ${ }^{14}$ The effect of the variable of labor income above the cap is also positive, which means that individuals with higher labor incomes are more likely to collect income from the old-age pension. For high earners, the decision to collect old-age pension is more complex and the income from the national pension system might be less important than income from occupational pensions. The incentive effects that exist for deferring the pension decision in the national system are not as clear in the occupational pension system. Note also the age effect, which indicates that the probability of collecting old-age pension increases with age at an accelerating rate.

Table 7 shows the results for the model that determines pension size, assuming collection of old-age pension. The model was estimated using OLS and uses only data from 2011. As shown, the replacement rate is signifi-

14 It should be mentioned that interpretation of the estimated parameters in this type of model is complicated. This complexity is partly due to that this is a nonlinear model and partly to that the intercept in the model is stochastic. If, despite this caution and assuming certain conditions, we calculate the elasticity of the replacement rate, we arrive at a value on the order of 0.2. An increase of the replacement rate by one percent thus increases the probability of collecting income from old-age pension by 0.2 percent. Using a simulation, which was the method used when the models were used in SWEtaxben, is a better method of estimating the effect of the size of the estimated parameters. 
Table 6: Probability of collecting old-age pension.

\begin{tabular}{lcc}
\hline Variables & Men & Women \\
\hline Intercept & $771.6555^{\star \star \star}$ & $1244.0820^{\star \star \star}$ \\
Initial value & $12.5024^{\star \star \star}$ & $10.4820^{\star \star \star}$ \\
2010 & $3.2093^{\star \star \star}$ & $2.4360^{\star \star \star}$ \\
2011 & $4.0886^{\star \star \star}$ & $3.3542^{\star \star \star}$ \\
Age & $-25.9246^{\star \star \star}$ & $-40.5899^{\star \star \star}$ \\
Age 2 /100 & $21.4813^{\star \star \star}$ & $32.9001^{\star \star \star}$ \\
Compulsory school & $1.0436^{\star \star \star}$ & $0.7356^{\star \star \star}$ \\
Secondary school & $0.9632^{\star \star \star}$ & $0.5444^{\star \star \star}$ \\
Large city & $-0.3362^{\star \star \star}$ & $-0.3831^{\star \star \star}$ \\
Native-born & $0.8478^{\star \star \star}$ & $0.7693^{\star \star \star}$ \\
Replacement rate & $1.4188^{\star \star \star}$ & $1.4211^{\star \star \star}$ \\
Income above cap & $0.4773^{\star \star \star}$ & 0.1591 \\
\hline
\end{tabular}

Table 7: Size of old-age pension assuming collection.

\begin{tabular}{lcc}
\hline Variables & Men & Women \\
\hline Constant & $11.560^{\star \star \star}$ & $11.198^{\star \star \star}$ \\
61 & $-1.028^{\star \star \star}$ & $-1.146^{\star \star \star}$ \\
62 & $-0.731^{\star \star \star}$ & $-0.829^{\star \star \star}$ \\
63 & $-0.605^{\star \star \star}$ & $-0.720^{\star \star \star}$ \\
64 & $-0.519^{\star \star \star}$ & $-0.568^{\star \star \star}$ \\
65 & $-0.383^{\star \star \star}$ & $-0.354^{\star \star \star}$ \\
Compulsory school & $-0.534^{\star \star \star}$ & $-0.339^{\star \star \star}$ \\
Secondary school & $-0.344^{\star \star \star}$ & $-0.212^{\star \star \star}$ \\
Large city & $0.103^{\star \star \star}$ & $0.109^{\star \star \star}$ \\
Native-born & $0.385^{\star \star \star}$ & $0.250^{\star \star \star}$ \\
Replacement rate & $1.010^{\star \star \star}$ & $1.292^{\star \star \star}$ \\
Replacement rate & $-0.173^{\star \star \star}$ & $-0.246^{\star \star \star}$ \\
\hline
\end{tabular}

cant and the estimated effect follows an inverted U-shape. Pension income thus rises with the replacement rate, but at a decelerating rate. ${ }^{15}$

An update of SWEtaxben with the models described above combined with calibration to arrive at working hours and working income provides an opportunity to simulate the combination of labor/pension income. This new structure is used in the next section to evaluate the existing JSA for older workers as well as a somewhat modified version of the same.

15 Based upon the estimated model, it can be calculated that maximum pension income is attained at a value of almost 3 . This is an extremely high value for the replacement rate; that is, a pension income that is three times higher than labor income. As only a very few individuals have such a high replacement rate, this means that an increase in the replacement rate entails an increase in pension income for virtually all individuals in the sample.

\subsection{Reform Evaluations using a General Model}

Two reforms are evaluated in this section: the one that was actually implemented and one hypothetical. The implemented reform is the increased JSA as currently designed and the hypothetical reform is an expanded increased JSA offered to all workers over the age of 60 . These two reforms are evaluated by comparing them with a tax system that does not include the increased JSA. In this tax system, all individuals receive the same JSA, regardless of age, and is thus the same that currently applies to everyone below the age of 66. The comparison population varies depending on which reform is evaluated. The evaluation of the current design of the increased JSA is based on all individuals age 66-70, while the equivalent for the expanded JSA is everyone age 61-70. In SWEtaxben, we make the somewhat simplistic assumption that everyone over age 70 is retired. We compare the outcome with and without behavioral effects and a summary of the results is presented in Table 8.

The results for the reform in which the JSA applies to people older than 65 are presented in columns (1) and (2). Without any behavioral modifications, the employment rate and labor/pension incomes are unchanged. The tax reduction of 1.0 percent that follows from the increased JSA increases disposable income and thus increases tax revenues from VAT. If all sub-components are mechanically totaled, we arrive at a total reduction of public finances of SEK 432 million. Without behavioral effects, the total cost of the increased JSA is thus calculated at SEK 432 million.

When household adjustments of pension collections and labor supply due to the increased JSA are taken into account, the consequence is relatively large. It turns out that the reform does not weaken public finances, but on the contrary strengthens them. The employment rate rises by more than 13 percent and working hours by 9 percent. This results in higher labor income and slightly lower pension income. Due to the increased labor income, the reduction in income tax revenues caused by implementing the JSA is no longer as large-a reduction of only 0.3 percent. The increase in labor income also generates a 3.7 percent increase in payroll taxes. The increase in labor income also results in higher disposable income, which generates higher VAT revenues. The total result for the public finances is a surplus of SEK 275 million; that is, the increased JSA generates income for the public finances. It should also be mentioned that the effect of changed transfer payments is included, but apart from pensions, these effects are small. The explanation for this is that the effect on household disposable income is not so large. 
Table 8: Evaluation of the increased JSA based on the 2014 rule system.

\begin{tabular}{|c|c|c|c|c|}
\hline & \multicolumn{2}{|c|}{ Increased JSA for people age 66 and older } & \multicolumn{2}{|c|}{ Increased JSA for people age 61 and older } \\
\hline & $\begin{array}{l}\text { Without behavioral } \\
\text { modification, } \\
\text { percent } \\
\text { (1) }\end{array}$ & $\begin{array}{l}\text { With behavioral } \\
\text { modification, } \\
\text { percent } \\
\text { (2) }\end{array}$ & $\begin{array}{l}\text { Without behavioral } \\
\text { modification, } \\
\text { percent } \\
\text { (3) }\end{array}$ & $\begin{array}{l}\text { With behavioral } \\
\text { modification, } \\
\text { percent } \\
\text { (4) }\end{array}$ \\
\hline Employment rate & 0 & 13.3 & 0 & 3.8 \\
\hline Working hours & 0 & 9.0 & 0 & 5.9 \\
\hline Pension income & 0 & -0.2 & 0 & -0.3 \\
\hline Labor income & 0 & 6.9 & 0 & 2.9 \\
\hline Income tax & -1.0 & -0.3 & -1.8 & -1.3 \\
\hline Transfers & 0 & 0 & 0 & -0.4 \\
\hline Disposable income & 0.4 & 1.1 & 0.7 & 1.3 \\
\hline VAT & 0.4 & 1.1 & 0.7 & 1.3 \\
\hline Payroll taxes & 0 & 3.7 & 0 & 2.0 \\
\hline $\begin{array}{l}\text { Total budget effect, } \\
\text { SEK millions }\end{array}$ & -432 & 275 & $-1,514$ & -66 \\
\hline
\end{tabular}
a tax system that does not include the increased JSA

How comparable are the results based on structural models and microsimulation with the earlier results based on DiD? As mentioned, the DiD results yield an employment effect of 8-19 percent (disregarding the highest value). As shown in Table 8 , the corresponding "structural" result of implementing the increased JSA is increased employment by about 13 percent. This is thus a comparable result, especially considering the earlier discussion of the comparability of the DiD evaluations. The more recent data used in this paper return a higher reform effect and it is also relevant to base the size of the effect on a comparison of the treatment group before the reform. Both of these factors indicate that a reform effect of about 13 percent is reasonable. However, one problem remains with the comparison because the earlier evaluations also included potential demand effects of reduced payroll taxes for older workers.

The main advantage of structural models is that hypothetical reforms can be evaluated. One question of interest is what effect a more generous JSA would have. Here, we choose to evaluate a reform in which everyone age 61 or older receives the increased JSA. At this lower age limit, it is possible to begin collecting the national old-age pension.

The results, which are presented on columns (3) and (4) in Table 8, include all individuals age 61-70. The expanded JSA brings an increase in employment and labor income while pension income declines. Compared with the previous evaluation, the negative effect on tax revenues is considerably larger. More individuals are included and, especially, considerably more who work and benefit from the JSA. Without behavioral modification, tax revenues decline by an estimated 1.8 percent. As this generates higher disposable income and higher total VAT revenues, the total budget effect amounts to a deficit of about SEK 1.5 billion. When we allow behavioral adjustments, the corresponding result is a deficit of only SEK 66 million.

The evaluation illustrates the importance of taking household adjustments into account, as well as that of including all effects of a reform on the various income and expenditure items in general government finances. The long-term effects that can be expected of a reform and how these differ from evaluations based only on a cross-section are discussed in the next section.

\subsection{Reform Evaluation Using a Long-Term Effects Model}

The long-term effect of the increased JSA is evaluated in this section. The evaluation includes both the current design, which applies starting at age 66 and the proposal to implement the JSA earlier, at age 61. The point of departure is a comparison with a situation in which there is no increased JSA, which is called the "reference alternative" in the following. Long-term effect here refers to the effect on public finances over a longer period of time. Any behavioral adjustments on the supply side after a reform are 


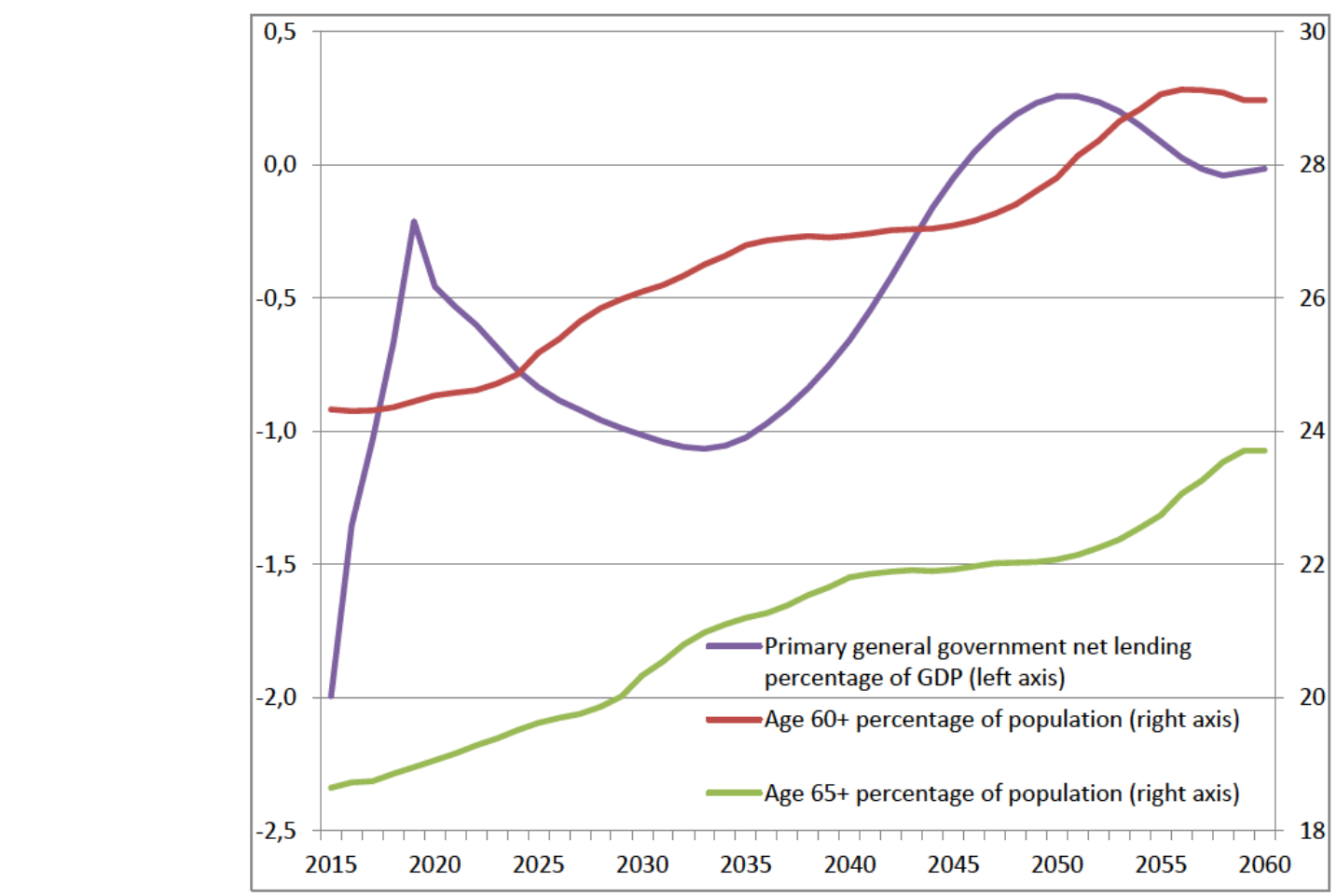

Source: Flood and Ruist (2015)

Figure 12: Primary general government net lending as a percentage of GDP and the percentage of older people in the population.

presumed immediate, and thereafter we study the effects this has on the capacity to finance the general government sector over the long term. The subject is thus not the longterm adjustment of individuals but the long-term effects on general government financing.

The method used in this section differs from that used in the preceding section with regard to both the income and expenditure items included and the difference in longterm and short-term. Comparisons may therefore be made only qualitatively and any difference in the size of the effects is of subordinate interest. One point of departure is based on a report of the long-term general government net lending presented in Flood and Ruist (2015); see Figure 12. General government income and expenditures have been calculated for each year until 2060, based upon the Ministry of Finance's long-term calculations, see Ministry of Finance (2015), combined with the microsimulation model SESIM. ${ }^{16}$ Income consists of personal and business tax revenues and expenditures consist of transfer payments to households and general government consumption. These calculations encompass all general government income and expenditures and, as mentioned, general government consumption is also included. It should also be emphasized that the SESIM calculation is performed at the individual level.

The crux here is that this type of description of the long-term financing of the general government sector may serve as a reference in the evaluation of reforms. The intention is not to discuss the credibility or the methods used to prepare these long-term forecasts. Other experts, such as the National Institute of Economic Research, make an even more pessimistic assessment of the development of general government net lending. ${ }^{17}$ The principle is what is important here, and not which underlying forecast was used. An assessment of a tax reform should be long-term and the aim should be to design reforms that can contribute as effectively as possible to financing the general government sector.

We have chosen to base our evaluation on the Ministry of Finance's assessment. The point of departure for 2015 is a total deficit of about two percent of GDP. This deficit is predicted to decline rapidly in the next few years before
16 SESIM is a dynamic microsimulation model developed by the Ministry of Finance in collaboration with researchers. See www.sesim. org.
17 See for example the in-depth discussion of the long-term sustainability of general government finances in the NIER report for March 2015. 


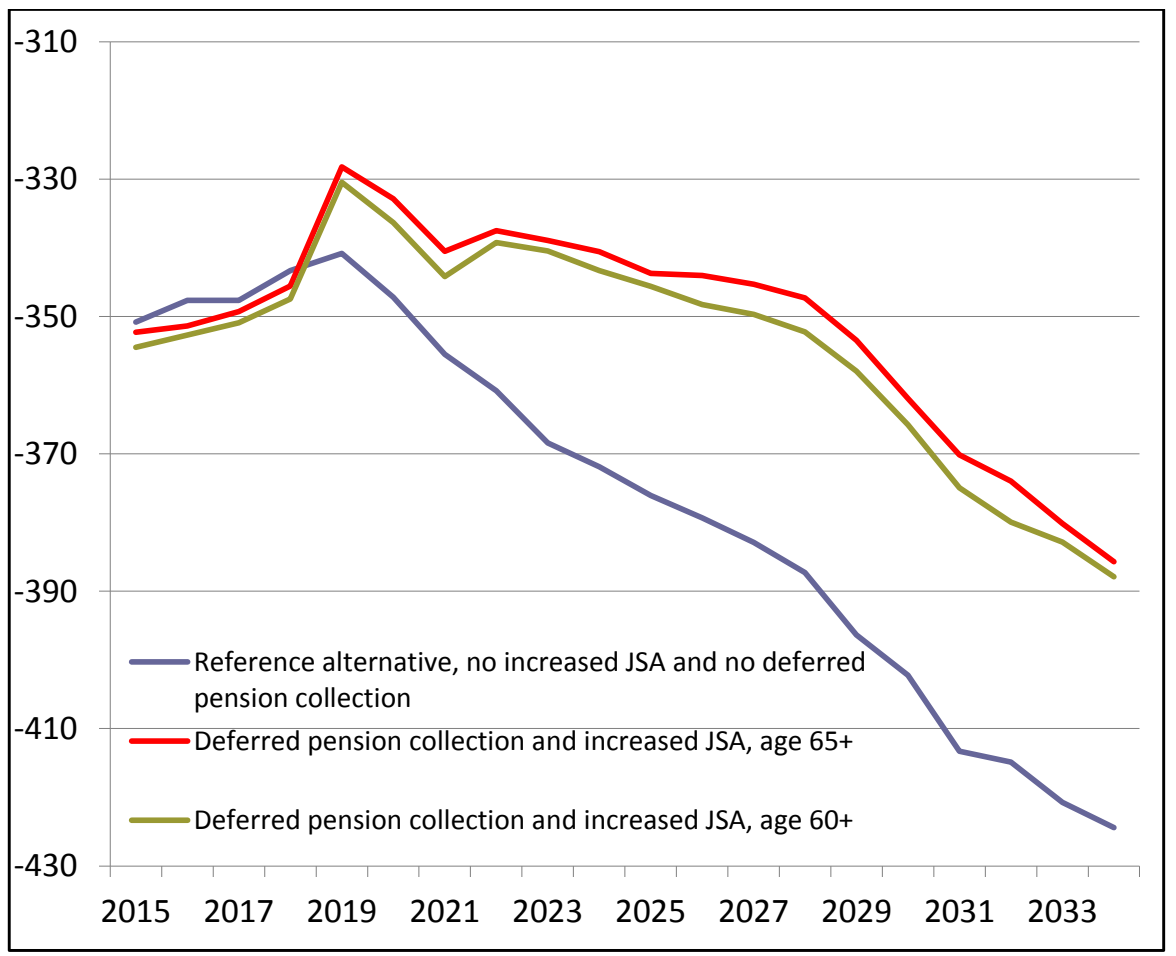

Figure 13: Primary general government net lending in SEK billions for those older than 60 and the period of 2015-2034.

rising again. According to the forecast, the deficit will persist until the mid-2040s, followed by a brief period of surplus until a balanced budget is attained at the end of the projection period.

The total net profile is largely explained by the age of the population. The sharp downturn in general government net lending from 2019 to 2035 reflects an aging Sweden. As shown in Figure 12, the percentage of older people in the population rises rapidly throughout the projection period. In 2015, individuals older than 65 make up 18.6 percent of the population and according to the forecast, this is expected to have risen to 23.7 percent by 2060. Expressed in the number of individuals, this is an increase of more than 1.3 million. Naturally, this entails a corresponding reduction in the percentage of the population who are of working age (20-64). In 2019 when the deficit is lowest, this group accounts for about 53 percent of the population and is expected to have declined to 48 percent by 2035. This results in a reduction in general government income, with direct taxes accounting for the largest reduction. The sharp upturn in general government net lending starting in 2035 and continuing to the end of the projection period is explained by that the percentage of older workers stops rising, and that the general population even becomes somewhat younger. The percentage of the population of working age increases modestly, to about 50 per- cent, and total income as a percentage of GDP rises compared with 2035 but is slightly below the 2019 level.

The evaluation of a forward-looking reform like the increased JSA should be seen from this perspective and the question is how great is the anticipated effect on long-term general government net lending.

In order to clarify the difference between the reference alternative (no increased JSA and no extended working life) and the alternative (increased JSA and extended working life), Figure 13 shows only the effect on net lending for people who are older than 60 and and only for the period of 2015-2034. The presentation concentrates on this age stratum because the reform being evaluated only affects older workers. In theory, the evaluation could be based on the entire population, but in order to clarify the results, it is advantageous to limit the analysis to the people who are affected by the reform. The choice of the long term, 2034, is governed by what appears to be a reasonable period considering that it is during this period that the deficit grows and the need for counter-balancing reforms is greatest. In contrast to Figure 12, net lending is defined in SEK billions and not as a percentage of GDP. ${ }^{18}$

18 Net lending has been deflated with an income index. The choice of index is open to discussion, but is governed here by that net lending is largely constituted of pension income and these are indexed in the 
Unsurprisingly, net lending is negative; for the reference alternative, the deficit varies from about SEK 350 billion in 2015 to about SEK 420 billion in 2034. These older individuals, above 60 , make only a small contribution to general government finances: low labor incomes generate low tax revenues. ${ }^{19}$ In parallel, expenditures are high and old-age pensions are the dominant item. The size of the deficit is primarily of less interest for our analysis. The interesting question is what change in the size of the estimated deficit would follow upon the reforms involving the increased JSA and thus a deferred exit from working life. To answer this question, we assume that the reforms generate an increase in employment in the form of later exit from the labor market for the 61-70 and 66-70 age strata during the period of 2015-2035 by slightly less than 6 percent on average. The choice of 6 percent is partially arbitrary and may seem low, considering the results presented earlier in which the effect of the targeted tax reductions was estimated at 8-19 percent. As these results also included the reduction of payroll taxes, there may be reason to stay below these levels.

As evident in Figure 13, the results show a sharp reduction in the deficit. In 2034, this reduction amounts to about SEK 37-39 billion, where the higher amount refers to the increased JSA for people older than 65 . The more generously defined proposal in which the JSA is implemented for people older than 60 results in a smaller reduction in the deficit, but the difference compared with the alternative where it is implemented for people older than 65 is not particularly great. The reason the reduction of the deficit is less when the JSA is implemented at age 61 is that this proposal entails a relatively large loss of tax revenues. Despite everything, a large percentage of the population age 61-65 is gainfully employed. For these people, the reform mainly entails lower tax on labor and thus lower tax revenues for the general government sector.

The reforms show a larger deficit in the initial years, which is explained by the assumption that the reforms are phased in to a certain extent, rather than taking full effect immediately. This is designed in such a way that the individual is assumed to adjust to a particular norm and that this norm increases during the projection period. During the period of 2015-2018, the norm is 65 , rising to 66

simulation by income growth or by an index closely linked to income growth.

19 It should be noted here that these older workers have of course contributed to the general government finances earlier in their lives, but since we are only looking at their net lending contribution when they are older, the expenditure side dominates. for 2019-2021 and finally to 67 for 2022-2034. A random spread around this norm also occurs, and it is possible to combine collection of old-age pension and work. As mentioned, the total effect on employment is an increase of 6 percent. ${ }^{20}$

Note that the calculation of general government net lending is based on all individuals older than 60 . The purpose of estimating general government net lending for all people older than 60 even though the employment effect of the reform is estimated only for those who are age 6670 when the reform refers to the increased JSA for people older than 65 and 61-70, when the JSA refers to those older than 60 , is that the potential changes that occur at $61-70$ and 66-70, respectively, have effects on general government net lending over a long period of time. For example, a person who chooses at age 66 to continue working for a year or two will gain higher disposable income for the rest of their life. This higher income reduces the need for income from the basic social security systems (reduced general government expenditures) and generates taxes (increased general government income). To include these effects, it does not suffice to limit the calculations for those in the $61-70$ and $66-70$ age strata.

To express the reform effects in a more compact way, a net present value estimate of general government net lending is presented for both the reference alternative and the two alternatives that entail longer working life. The net contribution for year $t$, calculated for all individuals older than 60 , may be expressed as

$$
N B_{t}=\sum_{i=1}^{N} I_{t i}-U_{t i} \quad t=2015, \ldots, T
$$

where $I_{t i}$, refers to all income to the general government sector that the individual pays in year $t$, and $U_{t i}$ are the expenditures by the general government sector that the individual receives in the same year. $N$ is the number of individuals older than 60 . In order to estimate the total net vis-à-vis the general government sector for 2015, the net present value of all future net contributions is calculated

20 That the effect of the reform can be phased in over time may seem to contradict the earlier description, where it was argued that the behavioral effect of the reform was immediate. It is important here to distinguish between the individual's supply of labor arising from the change in working hours preferred by the individual prefer and the realized working hours that are dependent upon the demand side and other restrictions in the labor market. Here, this can be interpreted to mean that employers' acceptance of and preference for retaining older workers increases with time. 
Table 9: Net present value of general government net lending in SEK billions and percentage change compared with the reference alternative. The calculations refer to the period of 2015-2035 and individuals older than 60 .

\begin{tabular}{lcccc}
\hline & \multicolumn{2}{c}{ SEK billions } & \multicolumn{2}{c}{$\begin{array}{c}\text { Percentage change compared with } \\
\text { reference alternative }\end{array}$} \\
\cline { 2 - 5 } & No discount & Discount rate 3\% & No discount & Discount rate 3\% \\
\hline Reference alternative & $-7,532$ & $-5,537$ & \\
Increased JSA at 66 & $-7,023$ & $-5,199$ & -6.7 & -6.1 \\
Increased JSA at 61 & $-7,085$ & $-5,243$ & -5.9 & -5.3 \\
\hline
\end{tabular}

as follows:

$$
B_{2015}=\sum_{t=2015}^{T} \frac{N B_{t}}{(1+r)^{t}}
$$

where $r$ is the discount rate and $T=2034$.

The results of this evaluation are presented in Table 9. At a discount rate of zero, the net present value of the deficit for the reference alternative is SEK 7,532 billion. At a discount rate of 3 percent, the corresponding deficit is SEK 5,537 billion. As mentioned, these calculated amounts are intended only to be used as a reference to assess the size of the long-term effects of the reforms that include the increased JSA. As shown in Table 9 and as already presented in Figure 13, the increased JSA (and thus the presumed extension of working life) significantly reinforces public finances. Compared with the reference alternative, a reduction of the deficit is expected on the order of 5-7 percent, depending upon the age at which the JSA is implemented and the choice of discount rate. Note that both the current system and the proposed lower age limit for the increased JSA are both overfunded. The degree of overfunding is somewhat higher for the reform with the higher age limit.

The results show a sharp reduction of the accumulated deficit compared with the corresponding deficit for the alternative without the increased JSA (and thus without higher employment). How can such a strong effect be explained? The most important reason is that the number of older workers increases during the period up to 2035. A strong argument in favor of the increased JSA is that this reform is well-adapted to an aging Sweden. This is also the most important difference compared to the earlier evaluation performed in section 2.4. The point of departure there was a change in the employment rate during a single year based on the number of older workers that year. The long-term analysis takes into account that the population of older people rises over time, and thus the population affected by the reforms, and that there is a large net contribution to the general government sector for every new individual who remains in work. The long-term ef- fects of general government net lending take into account several income and expenditure effects that were not included in the short-term evaluation presented in section 2.4. Additional years of work towards the end of working life generate higher tax revenues and payments into the pension system. On the expenditure side, gains are seen in the form of deferred pensions and lower expenditures for basic social security. This is a good example of double gains. This is a strong argument that a policy that creates incentives to defer pension collection can very well be both self-financed and overfunded over the long term.

The intention of the long-term evaluation is to illustrate the need for reforms that are adapted to future challenges. The most important of these are the expected demographic changes that will in all likelihood occur in the next few decades. Alternative evaluations are reported in the long-term calculations by the Ministry of Finance. These contain various future scenarios in which, for example, the effect of increased employment is included. The results are presented as various balance measurements, but the fundamental principle is the same. ${ }^{21}$ The difference compared with the presentation in this paper is that the point of departure here is the evaluation of economic reforms and the expected long-term effects of these reforms on public finances.

\section{Concluding Reflections}

The discussion about an aging Sweden has been ongoing for quite some time and the problem has been examined in many research reports and studies. Despite this, there is much to indicate that this issue deserves continued focus. Although most countries are facing more severe

21 The Ministry of Finance bases its calculations on two sustainability indicators, S1 and S2, both developed by the European Commission. These indicators are intended to quantify how much net lending must be adjusted to attain financial sustainability. 
challenges than Sweden, there is ample reason to study Swedish developments. Sweden has a reformed pension system that provides financial incentives for most people to defer the collection old-age pension. The targeted tax reforms for older workers intended to stimulate both labor supply and labor demand may be an even more important factor. The results presented in this paper argue that these reforms may be the reason that Sweden currently ranks first in Europe with regard to increasing the employment rate among older workers.

One message in this paper is that the essential issue is not when an individual decides to begin collecting their old-age pension, but rather the timing of the decision to leave the labor force. The issue of the transition from employment to retirement deserves attention. As shown in the paper, a large percentage of older workers currently have both labor income and pension income. For many people today, pension income is regarded as base income that may provide a foundation for pursuing an alternative career. There is good reason to encourage such a development, primarily because this entails an extended working life. The flexibility of the national pension system could play an important role here. This includes the right to collect old-age pension starting at age 61 and that people who continue working also continue to pay pension contributions and earn pension rights. The system allows a smooth transition from work to retirement and creates incentives to work longer.

In addition to the incentives to work longer created by the national pension system, the increased JSA for older workers is worthy of attention. The main message of this paper is that this tax reduction is an important explanation for the high labor supply among older workers. Evaluations using different methods show that this reform has had an effect on the employment rate. An evaluation of the effect on public finances shows that this reform is not only self-financed, but overfunded-and sharply overfunded long term. A net present value calculation based on a discount rate of 3 percent shows a bolstering of public finances on the order of SEK 300 billion by 2034. This is an argument in favor of proposing an expansion of the increased JSA. Such an expansion is evaluated in which the minimum age is lowered from 66 to 61 . The evaluation shows that such a reform can help reduce the deficit in public finances over the long term. It should also be emphasized that this alternative, compared with the current design in which the JSA takes effect at age 66, entails a somewhat lower degree of overfunding. Given the uncertainty associated with long-term projections, this can be used as an argument for not implementing a sharp reduction in the age of eligibility for the increased JSA. Despite everything, the employment rate for people under 65 is relatively high and for those who are already working, the JSA mainly entails lower tax revenues for the general government sector. There may be reason here to further evaluate the effect of a more modest lowering of the age limit, to 64 or 65 , for example.

The paper accentuates the need for a long-term perspective when evaluating economic reforms. The longterm effects of general government net lending take into account several effects on both the income and expenditure sides of the budget. Additional years of work towards the end of working life generate higher tax revenues and payments into the pension system. On the expenditure side, gains are seen in the form of deferred pensions and lower expenditures for basic social security. This is a good example of double gains. Purely hypothetically, it is also possible that the increased stability in the pension system brought about by deferment of pension collection could affect the balance in such a direction that the balancing mechanics are not activated, or are activated with less force. This in turn will have "dynamic effects" in that the reduction of retirees' incomes does not cause a reduction in tax revenues.

Naturally, it can also be argued that the number of years in work is what counts. This may be achieved through earlier entry, for example, which results in more earned pension rights and less pressure on the basic security of the pension system. There are two arguments that deferred exit is to be preferred. First, education is a logical alternative and often a reason for late entry, but with regard to exit, the existence of alternatives with equally high financial returns in the future is by no means self-evident. The second argument is that labor income near the end of working life is considerably higher than income during the early years. The size of labor income is an important reason for the relatively large positive effects shown in the longterm evaluation and it is these higher incomes that generate both higher pension rights and tax revenues.

Finally, it is noteworthy that an economic evaluation of reforms is normally based on the effect of the reform on individual welfare and the welfare of society as a whole, and not primarily the effect on general government finances. Proposing and designing reforms in which both welfare and general government net lending are affected in a positive direction is a challenge for the future. 


\section{References}

Edin, Per-Anders and Peter Fredriksson, (2000), "LINDALongitudinal INdividual DAta for Sweden", Working Paper 2000:19, Department of Economics, Uppsala University.

Ericson, Peter, Lennart R. Flood, Roger Wahlberg, 2009, “SWEtaxben: A Swedish Tax/benefit Micro Simulation Model and an Evaluation of a Swedish Tax Reform", IZA DP No. 4106

Eurostat (2014), Labour force survey statistics - transition from work to retirement. http://ec.europa.eu/eurostat/statisticsexplained/index.php/Labour_force_survey_statistics_-_transitio n_from_work_to_retirement

Finansdepartementet (2012) [Ministry of Finance], "Utvärdering av jobbskatteavdraget,” Government Bill 2011/12:100, Appendix 5.

Finansdepartementet (2015) [Ministry of Finance], Utvecklad bedömning av finanspolitikens långsiktiga hållbarhet 2015, memorandum to Spring Budget Bill 2015.

Flood, Lennart R. (2008), "SESIM: A Swedish Micro-Simulation Model," Simulating an Ageing Population: A Microsimulation Approach Applied to Sweden. Edited by Anders Klevmarken and Björn Lindgren. Emerald Group Publishing Limited, Howard House UK, pp. 55-83, ISBN 978-0-444-53253-4.

Flood, Lennart R. and Joakim Ruist (2015), “Migration, en åldrande befolkning och offentliga finanser," Appendix 6 to the Long Term Economic Survey 2015, Swedish government report SOU 2015:95, http://www.regeringen.se/contentassets/6a0373dacf97488d8a ae6b5785e46583/migration-en-aldrande-befolkning-och-offentli ga-finanser-sou-201595
Flood, Lennart R. (2016), "Skatt, arbete och pension," Rapport Svenskt Näringsliv, Stockholm 2016. http://www.svensktnarings liv.se/migration_catalog/Rapporter_och_opinionsmaterial/Rapp orter/skatt-arbete-och-pensionpdf_645628.html/BINARY/Skatt, \%20arbete\%20och\%20pension.pdf

Konjunkturinstitutet (2015 [National Institute of Economic Research], "Swedish Economy, March 2015."

Pirttilä, Jukka and Håkan Selin (2011), "Tax Policy and Employment: How Does the Swedish System Fare?” Working Paper 2011:2, Department of Economics, Uppsala University.

Puhani, Patrick (2012), "The treatment effect, the cross difference, and the interaction term in nonlinear "difference-in-differences" models" Economics Letters, Vol 115, no. 1.

Laun, Lisa (2012), "The Effect of Age-Targeted Tax Credits on Retirement Behavior," IFAU Working Paper 2012:18, Institute for Evaluation of Labour Market and Education Policy.

Pensions Agency (2015), Medelpensioneringsålder och utträdesålder 2014, https://www.pensionsmyndigheten.se/Medelpensionering saldernUttradesaldern2014.html

Skattebetalarna (2015) [Swedish Taxpayers Association], Andelen arbetande seniorer ökar snabbast i hela EU. 